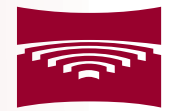
RĪGA STRADIN̦Š UNIVERSITY

\title{
Rūdolfs Cešeiko
}

\section{Maximal Strength Training for Breast Cancer Patients Undergoing Adjuvant Treatment}

Summary of the Doctoral Thesis for obtaining a doctoral degree (Ph.D.)

Sector - Health and Sports Sciences Sub-Sector - Sports Medicine and Rehabilitation 


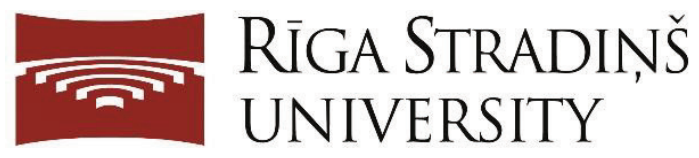

\author{
Rūdolfs Cešeiko \\ ORCID 0000-0002-2395-1306
}

\title{
Maximal Strength Training for Breast Cancer Patients Undergoing Adjuvant Treatment
}

Summary of the Doctoral Thesis for obtaining a doctoral degree (Ph.D.)

Sector - Health and Sports Sciences

Sub-Sector - Sports Medicine and Rehabilitation

Riga, 2021 
The Doctoral Thesis was developed at the Oncology Center of Latvia, Department of Breast Surgery and at the Department of Rehabilitation, Rìga Stradiņš University, Latvia

Supervisors of the Doctoral Thesis:

Dr. med., Associate Professor Signe Tomsone,

Rīga Stradiņš University, Latvia

Dr. med., Professor Eivind Wang,

Norwegian University of Science and Technology

Scientific Advisors:

Dr. med., Professor Jānis Eglītis, University of Latvia

Dr. med., Professor Aivars Vētra, Rīga Stradiṇš University, Latvia

Official Reviewers:

Dr. med., Associate Professor Iveta Kudaba, Rīga Stradiņš University, Latvia

Ph.D., Professor Aija Kḷaviņa, Latvian Academy of Sports Education

Ph.D., Professor Jan Hoff, Norwegian University of Science and Technology

Defense of the Doctoral Thesis will take place at the public session of the Promotion Council of the Basic Sciences of Medicine, including Health and Sports sciences on 11 August 2021, at 14.00 in Hippocrates Lecture Theatre, 16 Dzirciema Street, Rīga Stradiňš University, and using the Zoom platform.

The Doctoral Thesis is available in RSU Library and on RSU website: https://www.rsu.lv/en/dissertations

Secretary of the Promotion Council:

Dr. med., Associate Professor Inese Gobina 


\section{Table of content}

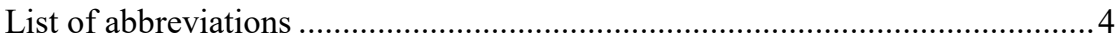

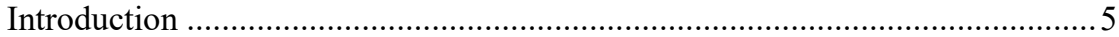

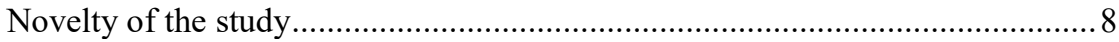

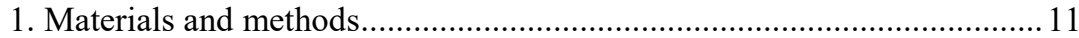

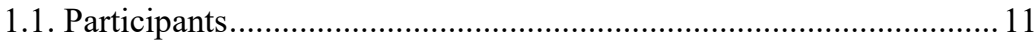

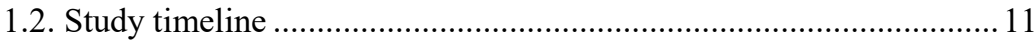

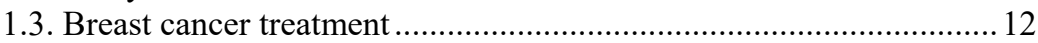

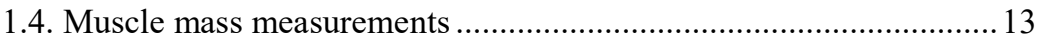

1.5. Maximal muscle strength measurements ....................................... 14

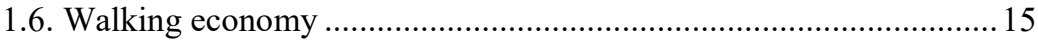

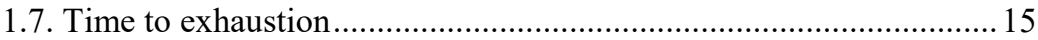

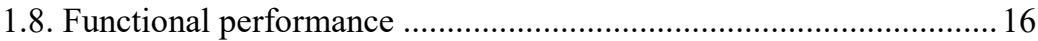

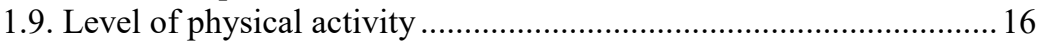

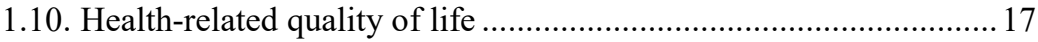

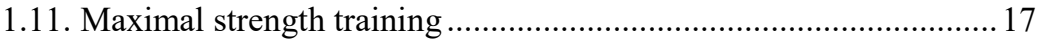

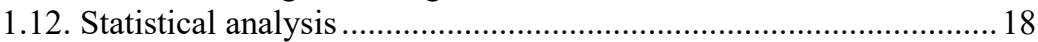

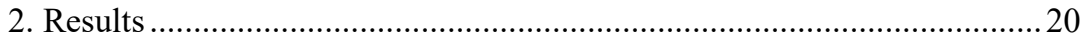

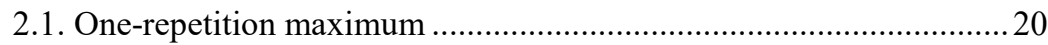

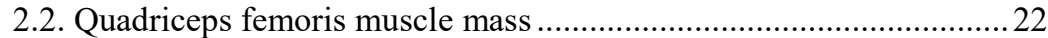

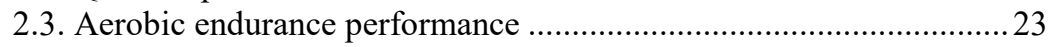

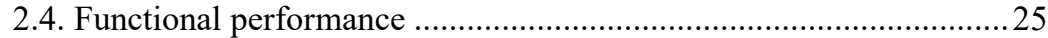

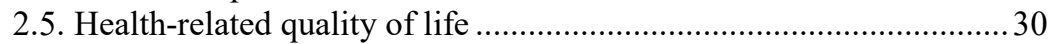

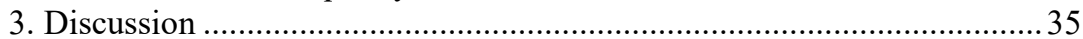

3.1. Muscle strength following maximal strength training.......................36

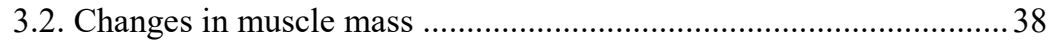

3.3. Functional performance .................................................................. 41

3.4. Maximal strength training improves walking economy ................... 42

3.5. Tolerance of the high-intensity program ......................................... 44

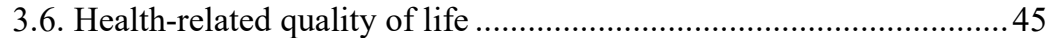

3.7. Strengths and limitations of the study .............................................. 48

3.8. Clinical implications for cancer rehabilitation ................................. 49

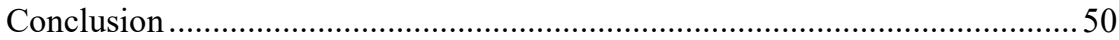

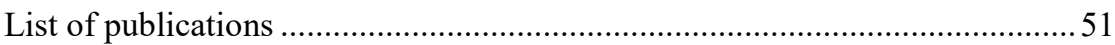

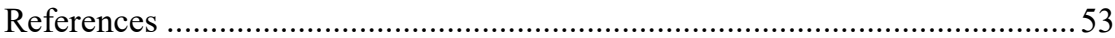

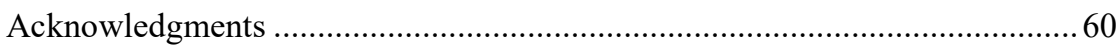




\section{List of abbreviations}

BC Breast cancer

HRQoL Health-related quality of life

EORTC The European Organisation for Research and Treatment of Cancer

QoL Global health status/QoL (Presented in EORTC)

MST Maximal strength training

1RM One repetition maximum

Mqf Quadriceps femoris muscle mass

6MWD Six minutes walking distance

LBM Lean body mass

RFD Rate of force development

DNA Deoxyribonucleic acid

WHO World Health Organization

ICF The International Classification of Functioning, Disability and Health

CRF Cancer related fatigue

BMD Bone mineral density

DEXA Bone densitometry

$\mathbf{V O}_{2 \max } \quad$ Maximal oxygen uptake

ACSM American College of Sports Medicine

COPD Chronic obstructive pulmonary disease

PAD Peripheral arterial disease 


\section{Introduction}

Breast cancer (BC) is the most frequently diagnosed type of cancer among women, with more than 2 million new cases and over 600000 deaths annually (Bray et al., 2018), and its global incidence is steadily rising. BC patients through the cancer continuum experience complex health and psychosocial challenges. $\mathrm{BC}$ and anti-cancer treatment accompanied by an inactive lifestyle may further impair muscle strength and muscle force development characteristics. Historically, patients diagnosed with cancer were advises to rest and avoid vigorous activity following their diagnosis, but this dogma has changed markedly over the last 20 years as exercise oncology intervention studies have gained broad acceptance and acknowledgment. Strength training can optimally affect muscles and increased muscle strength may contribute to participation in daily activities, thus potentially improving the health-related quality of life (HRQoL). However, the optimal type, intensity and frequency of strength training, as a part of cancer care, that will most enhance muscle strength during anti-cancer treatment is yet unknown.

Christensen et al. (Christensen et al., 2014) investigated newly confirmed (breast, gastric, colorectal, lung and pancreas) cancer patients and concluded that these patients had $0.9 \mathrm{~kg}$ lower muscle mass compared with healthy controls even before the initiation of anti-cancer treatment. Furthermore, during adjuvant chemotherapy, BC patients lost $1.3 \mathrm{~kg}$ lean body mass (LBM), and continued to lose LBM after therapy was completed. Ultimately, BC survivors evaluated after completion of primary therapy displayed 20-30\% lower muscle strength compared with healthy counterparts. Most physical activity interventions for BC patients combine aerobic endurance training with strength training and diverse relaxation therapies, hence making it more complicated to evaluate the impact of training type. There has been a limited number of well-defined clinical trials on 
$\mathrm{BC}$ patients that include higher intensity strength training, moreover when intervention is administered during adjuvant treatment.

Training intensities vary substantially across cancer studies ranging from $25-80 \%$ of one-repetition maximum (1RM), although, it has been documented that higher training intensities yield greater strength gains in young healthy individuals (Campos et al., 2002). Similarly, greater gains in muscle strength are documented with increasing intensity for cancer patients, however, these patients are likely to have some improvement even at low training intensities (Fairman et al., 2017). The common consent from clinical trials when strength training interventions were applied for cancer patients states that training programs were well tolerated, they are safe, feasible and showed strength improvements that led to improved physical functioning and improved HRQoL (Segal et al., 2003), (De Backer et al., 2007), (Battaglini et al., 2014). Recognizing that training intensity during strength training is a key factor to improve maximal muscular strength and strength related characteristics. Therefore, well-defined training methods with high intensity could also be preferable to induce greater physiological adaptations, thus contribute to faster recovery from specific cancer treatment and enhancing the completion of prescribed anti-cancer treatment.

\section{Aim of the study}

The Aim of this doctoral thesis was to investigate the effects of maximal strength training (MST) on one-repetition maximum (1RM), functional performance, walking economy, muscle mass and health-related quality of life (HRQoL) in women with I-III stage breast cancer undergoing adjuvant chemotherapy. 


\section{Objectives of the study:}

- Explore the effect of leg press MST on muscle strength of lower extremities, applying high training intensity $\sim 90 \%$ of one-repetition maximum (1RM) and emphasizing maximal intended velocity in the concentric phase of the movement.

- Elucidate weather MST has an impact on quadriceps femoris muscle mass (Mqf) for BC patients during treatment.

- Explore whether MST affects aerobic endurance capacities.

- To investigate MST induced effects on functional performance applying standardized functional tests before and after the intervention.

- To determine whether MST has an impact on HRQoL using the European Organisation for Research and Treatment of Cancer (EORTC) core questionnaire (C30) and supplementary questionnaire (BR23).

\section{Hypothesis of the study}

Twelve weeks of MST with emphasis on maximal mobilization of force in the concentric action will increase maximal muscle strength of lower extremities and result in improved functional performance, walking economy, HRQoL, and maintain muscle mass during adjuvant chemotherapy. In contrast, maximal strength, functional performance, walking economy, muscle mass, HRQoL would decrease following adjuvant chemotherapy without strength training. 


\section{Novelty of the study}

Anti-cancer treatment and inactivity following $\mathrm{BC}$ diagnosis induce loss of muscle strength and thus have created a large number of BC patients with very low physical capacities. Despite the well-documented neuromuscular and functional adaptations resulting from strength training, very few studies, quite surprisingly, have investigated the effects of strength training in the early critical phase of BC treatment. Furthermore, the few previous studies (Courneya et al., 2007b), (Battaglini et al., 2007), (Campbell et al., 2012), (Cheema et al., 2008) that have applied clinical strength training also appear to have applied low to moderate loading intensities ( $<75 \%$ of $1 \mathrm{RM})$. Results from studies document reduced lower extremity muscle strength following chemotherapy for $\mathrm{BC}$ (Schwartz and Winters-Stone, 2009) and others present no relevant effects (Buffart et al., 2020; Cornette et al., 2016; Courneya et al., 2007a; Mijwel et al., 2018b; Schmidt et al., 2015; Travier et al., 2015; van Waart et al., 2015a).

Of note, aerobic endurance related exercise interventions are the primary choice for cancer patients during clinical trials. Thus, few trials that involve strength training are gaining its recognition but still adds to a conflicting body of evidence that inconsistency between observations may be attributable to the type, duration and cumulative dose of chemotherapy. Typically, strength training interventions in an oncology setting include conventional strength training methodology witch is characterized using low to moderate intensity $25-75 \%$ of 1RM, using 1-3 sets with 8-12 repetitions in each set, with a slow movement in the concentric phase, interventions last from 4 weeks to 12 months, typically including cancer survivors and initiating strength training once treatment is completed (Buffart et al., 2020; Cornette et al., 2016; Mijwel et al., 2018b; Schmidt et al., 2015).

To our knowledge, there are no studies that have applied high-intensity strength training methodology in $\mathrm{BC}$ setting and especially during adjuvant 
chemotherapy. Therefore, in this study, MST to induce neural adaptations using few repetitions $(\leq 5)$ with a higher intensity $(\sim 85-95 \% 1 \mathrm{RM})$, and resting periods longer than $\geq 3$ minutes between sets, 2 times a week for 12 weeks was applied, moreover, training was carried out during adjuvant chemotherapy. Importantly, the dynamic leg press apparatus was chosen as a testing and training modality not only because it closely reflects functional performance during daily tasks (Unhjem et al., 2017), but also involves multi-joint execution in the lower extremities.

Recognizing the adverse early phase side effects of adjuvant therapy, in particular, due to the impact of anthracyclines, and low functional status immediately after treatment it remains unknown whether high-intensity strength training could yield similar neuromuscular and functional effects as observed in other patient populations, and whether it is feasible in BC patients shortly after surgery.

Importantly, in the Republic of Latvia medical rehabilitation for cancer patients is limited, and not all effective strength exercise methods have been recognized. As concluded by Health authorities - rehabilitation for patients with cancer are lacking and for a long time has not been a priority (L.R.V.K, 2018). A decrease in physical capacities and functionally are expected, especially during the early phase of treatment (Klassen et al., 2017), thus as a result of impaired physical capacities majority of patients are more likely to experience reduced HRQoL (Møller et al., 2020).

Therefore, ascertain the growing number of BC patients and survivors, theses thesis covers an important knowledge of strength exercise benefits for BC patients and could encourage health care professionals and health policymakers to use this information and results for an innovative, cost-effective and timeefficient strategy to develop effective rehabilitation programs, and further contribute to exercise oncology research field. 


\section{Personal contribution}

The author of the study has carried out all pre and post-testing (110 procedures), supervised and carried out 1248 training sessions. Collected scientific data, interpreted data, performed the statistical analysis and has written these theses.

\section{Structure and volume of the Doctoral Thesis}

The Doctoral Thesis was written in English language. Thesis consists of four chapters - literature review, methods, results, discussion - and conclusion. The thesis is written on 93 pages, including 6 tables, 8 figures and two original articles. 


\section{Materials and methods}

\subsection{Participants}

A 57 of newly diagnosed stage I-III BC patients scheduled for adjuvant treatment at the Oncology Center of Latvia, Riga participated in the study. Inclusion criteria were females between 18-63 years of age with newly $(<3$ weeks) diagnosed stage I-III invasive $\mathrm{BC}$, assigned for treatment with lumpectomy /mastectomy, and adjuvant therapy (radiation therapy and/or adjuvant chemotherapy). Exclusion criteria were verified heart disease, diabetes, musculoskeletal disorders of lower extremities or any disorder that prohibited participation in the testing procedures or maximal strength training (MST). Patients were randomized into an MST group or control group. Before randomization patients were stratified into 3 blocks based on diagnosed $\mathrm{BC}$ stage, stage I, stage II and stage III respectively, then patients in each block using block randomization were randomized to the MST group or control group. Shortly after inclusion and before randomization, 2 patients (mean age 52 years) dropped out due to family or work circumstances. Therefore, 55 patients (MST group; $\mathrm{N}=27$ ), (Control group; $\mathrm{N}=28$ ) were randomized and completed the study (Table 2.1.). The study was performed in accordance with the Declaration of Helsinki and was approved by the Ethics Committee of Riga Stradiņš University and the Scientific Department of Riga East University Hospital.

\subsection{Study timeline}

Included patients attended a standardized 1.5 -hour testing procedure 2-3 weeks' post-surgery. The aim was to initiate MST as soon as possible postoperation, after the surgeon's approval that the healing process on the operated site was without complications. After this was confirmed, patients were 
randomly allocated 1:1 to standard treatment with or without 12 weeks of supervised MST. The patients allocated to the MST group started their training 1-2 days after the testing and 1 week before receiving adjuvant therapy, subsequently all patients trained during adjuvant therapy. After 12 weeks, the 1.5-hour testing procedure was repeated (Figure 2.2.). The testing procedure started with measurements of quadriceps femoris muscle mass (Mqf), then patients continued with a battery of functional performance tests. Following a short break, dynamic maximal muscle strength of the lower extremities was assessed, then patients continued with walking economy and time to exhaustion testing. Finally, patients completed HRQoL questionnaires.

\subsection{Breast cancer treatment}

All included patients were treated according to the European Society for Medical Oncology (ESMO) and the National Comprehensive Cancer Network (NCCN) guidelines. Surgery consisted of oncoplastic lumpectomy or mastectomy and sentinel node biopsy or axillary node dissection. After surgery, patients were scheduled for adjuvant anti-cancer therapy potentially receiving chemotherapy and/or radiation therapy and/or Trastuzumab and/or endocrine therapy. Chemotherapy consisted of 4-8 cycles of doxorubicin $(50-60 \mathrm{mg} \cdot \mathrm{m}$ 2) or epirubicin [60-90 $\mathrm{mg} \cdot \mathrm{m}-2]$ and cyclophosphamide $(600 \mathrm{mg} \cdot \mathrm{m}-2)$ administered once every third week. Following the completion of anthracycline, some patients were furthermore scheduled to 4 cycles of paclitaxel $(135-175 \mathrm{mg}$ - $\mathrm{m}-2)$ or docetaxel (75-100 $\mathrm{mg} \cdot \mathrm{m}\urcorner-2)$ administered once every third week. Patients with HER2-positive tumors were treated with 18 cycles of trastuzumab (600 $\mathrm{mg} \cdot \mathrm{m}-2)$ administered once every third week after completion of chemotherapy. Some patients received endocrine therapy (aromatase inhibitors and/or tamoxifen) and biphosphates following completion of chemotherapy (Table 1.1.). 
Table 1.1.

Anthropometric parameters and treatment

\begin{tabular}{lcll}
\hline & $\begin{array}{l}\text { MST group } \\
\text { (n=27) }\end{array}$ & $\begin{array}{l}\text { Control group } \\
\text { (n=28) }\end{array}$ & P-value \\
\hline Age (years) & $48 \pm 7$ & $49 \pm 8$ & 0.69 \\
Bodyweight (kg) & $77.0 \pm 15.2$ & $72.3 \pm 17.4$ & 0.29 \\
Height (cm) & $170 \pm 6$ & $167 \pm 6$ & 0.07 \\
Disease stage, TNM & & & 0.57 \\
classification (\%) & & & \\
$\quad$ IA, IB & $9(33)$ & $13(46)$ & \\
IIA, IIB & $12(44)$ & $9(32)$ & \\
IIIA, IIIB, IIIC & $6(23)$ & $6(22)$ & \\
Surgery (\%) & & & \\
Lumpectomy & $16(59)$ & $22(78)$ & \\
SSM & $5(19)$ & $4(14)$ & \\
AB & $4(15)$ & $1(4)$ & \\
MRM & $2(7)$ & $1(4)$ & \\
Adjuvant therapy (\%) & & & \\
Radiation & $23(85)$ & $26(92)$ & 0.42 \\
Anthracyclines & $25(93)$ & $24(86)$ & 0.70 \\
Cyclophosphamides & $14(52)$ & $17(61)$ & 0.51 \\
Taxanes & $16(59)$ & $16(57)$ & 0.88 \\
Trastuzumab & $3(11)$ & $3(10)$ & 0.99 \\
$\quad$ Endocrine therapy & $15(44)$ & $15(46)$ & 0.75 \\
\hline Con
\end{tabular}

Continuous variables are presented as mean \pm standard deviation and categorical variables are presented as $\mathrm{n}(\%)$. SSM; skin-sparing mastectomy; $\mathrm{AB}=$ Amputation of the breast; MRM $=$ Modified radical mastectomy.

\subsection{Muscle mass measurements}

Quadriceps femoris (Mqf) was assessed by the following steps: the volume $(\mathrm{V})$ of the left thigh was estimated using the following equation (Layec, Venturelli et al., 2014):

$\mathrm{V}=\mathrm{L} \cdot 12 \pi^{-1} \cdot\left(\mathrm{C}^{2}+\mathrm{C} 2^{2}+\mathrm{C} 3^{2}\right)-(\mathrm{S}-0.4) \cdot 2^{-1} \cdot \mathrm{L} \cdot(\mathrm{C} 1+\mathrm{C} 2+\mathrm{C} 3) \cdot 3^{-1}$

Utilizing standard measuring tape, the thigh-length (L) was measured from the lateral femoral epicondyle to the greater trochanter. The thigh circumferences were measured at the midpoint $(\mathrm{C} 1)$ and $10 \mathrm{~cm}$ distal $(\mathrm{C} 2)$ and $10 \mathrm{~cm}$ proximal $(\mathrm{C} 3)$ of the midpoint. Further, at the midpoint three skinfold 
measures (S) were made: medial, anterior and lateral, and was then averaged for the whole thigh using skinfold caliper (SH5020, Saehan Corporation, MD, South Korea). Quadriceps femoris muscle mass (Mqf) was calculated as $\mathrm{Mqf}=0.307$. $\mathrm{V}+0.353 \mathrm{~kg}$ (Radegran, Blomstrand et al., 1999).

\subsection{Maximal muscle strength measurements}

Before all strength measurements, a warm-up procedure, consisting of $2-$ 3 sets of 6-8 repetitions was conducted. Maximal dynamic leg press strength for lower extremities was measured as 1RM in a horizontal leg press apparatus (Cybex Eagle 1040, USA). Starting from a near $180^{\circ}$ knee-joint angle, the patients were instructed to move slowly to a $90^{\circ}$ knee-joint angle, after which they moved concentrically back to the initial position (Figure 1.1.). The load was increased by $2.5-7.5 \mathrm{~kg}$ until the patients were unable to complete the lift. 1RM was defined as the heaviest lifted load and was typically obtained within 3-6 attempts. Rest periods of a minimum of 3 minutes were applied between each lift.
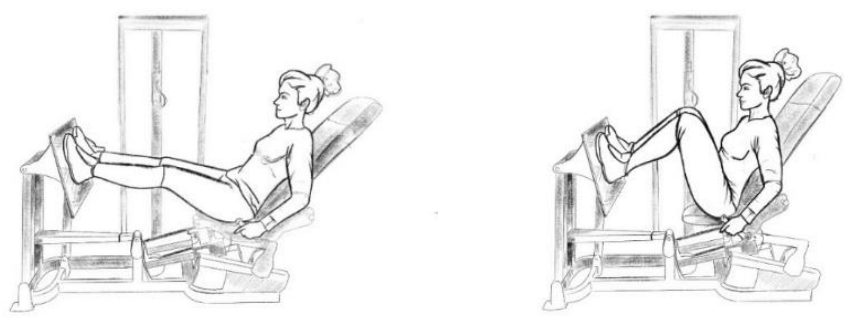

Figure 1.1. One repetition maximum testing and training using dynamic leg press apparatus 


\subsection{Walking economy}

The submaximal walking economy was assessed during the submaximal walking exercise on a treadmill. Before the test patients were familiarized with treadmill walking. Following a 5-minutes warm-up at a self-chosen speed, patients continued with a 5 minutes submaximal walking economy test, performed on a motorized treadmill (Spirit CT 100, Jonesboro, USA) at 5\% inclination. The speed was calculated to yield a workload of 40 Watt for the individual patient, using the following equation (Høydal, Helgerud et al., 2007):

$$
\text { Speed }\left(\mathrm{Km} \cdot \mathrm{h}^{-1}\right)=\frac{40 \mathrm{Watt}}{\left[\mathrm{m}_{\mathrm{b}} \cdot \mathrm{N}\right] \cdot \sin \theta} \cdot 3.6
$$

where $\mathrm{mb}$ is the individual patient's body mass, $\mathrm{N}$ represents newton converted to $\mathrm{kg}$, and $\theta$ is the $5 \%$ inclination of the treadmill. Thus patients with different body mass would all walk on a work rate corresponding to 40 Watts, implying different walking speeds. The walking economy was defined as the average heart rate, using a heart rate monitor (Polar Electro FT7, Kempele, Finland) at the last minute of the 5 minutes $40 \mathrm{Watt}$ work rate. Besides, patients were asked to state their subjective rating of perceived exertion (Borg scale) (6-20) to assess perceived exertion and the end of the fifth minute.

\subsection{Time to exhaustion}

Following the submaximal walking economy test, patients commenced directly to the measurement of time to exhaustion. The speed was held constant at 3.8 or $4.8 \mathrm{~km} \cdot \mathrm{h}-1$, depending on the patient's condition, and the inclination was increased by $2 \%$ every minute. If the patient was able to continue after reaching an inclination of $12 \%$, the speed was increased by $0.5 \mathrm{~km} \cdot \mathrm{h}-1$ per minute until voluntary exhaustion (Wolthuis, Froelicher et al., 1977). The heart rate and perceived exertion (Borg scale) were recorded immediately after the exhaustion test. 


\subsection{Functional performance}

Battery consisting of three functional performance tests were applied. First, 6 minutes walking distance (6MWD) was measured. The patients were instructed to walk back, forth and around two cones separated $>20$ meters in length, with distance interval markings every $3-5$ meters, aiming to walk the longest possible distance in 6 minutes (Dobson, Hinman et al., 2013).

Second, chair rising ability was assessed by 30 seconds sit to stand test. Starting from a seated position with crossed arms, the patients were instructed to rise from a $44 \mathrm{~cm}$ high chair as many times as possible in 30 seconds (Guralnik, Simonsick et al., 1994).

Third, the stair climb test, ability to climb stairs was assessed as the time needed to ascend and descend 10 stair steps of $18 \mathrm{~cm}$ without the use of handrail support as quickly as possible, best out of two trials were recorded (Fiatarone, O'Neill et al., 1994).

\subsection{Level of physical activity}

Shortly before the scheduled operation (typically 1-2 days), patients were asked if they engaged in recreational physical activities weekly, applying the short form of the International Physical Activity Questionnaire (IPAQ - SF). The IPAQ aimed to determine the activity level of included patients in the present study. Previously, in The Republic of Latvia, A. Kaupužs (Kaupužs, 2011) used IPAQ in this Dissertation where it has been validated and retested. The IPAQ calculates average weekly physical activity level by estimating the metabolic equivalent of task (MET) score and accounts for the total number of minutes per week spent with low, moderate and vigorous-intensity activities (3.3, 4.0 and 8.0 MET-minutes/week, respectively). The IPAQ has previously been tested and documented to have good validity and reliability (Craig, Marshall et al., 2003). 
Additionally, patients were asked whether they specifically were involved in regular strength training for the last 6 months before diagnosis.

\subsection{Health-related quality of life}

HRQoL was measured by The European Organisation for Research and Treatment of Cancer quality of life questionnaire (EORTC QLQ-C30) a 30-item questionnaire (version 3.0) and an additional Breast cancer module (QLQ-BR23) (Aaronson, Ahmedzai et al., 1993). EORTC QLQ-C30 and QLQ-BR23 is a merged system for assessing HRQoL of cancer patients participating in clinical studies. The QLQ-C30 consists of multi-item scales and single-item measures. These include 5 functional scales (physical functioning, role functioning, emotional functioning, cognitive functioning, social functioning), 3 symptom scales, a global health status/QoL scale and 6 single items. Importantly that each of the multi-item scales includes a different set of items - no item occurs in more than one scale. Additionally, the QLQ-BR23 module consists of 23 questions assessing disease symptoms, side effects of treatment (surgery, chemotherapy, radiotherapy and hormonal treatment), body image, sexual functioning and future perspective (Aaronson, Ahmedzai et al., 1993). All of the scales and single-item measures range in scores from 0 to 100. A high score represents a higher response level. Thus, a high score for a functional scale represents a high/healthy level of functioning, a high score for the global health status /QoL represents high QoL, but a high score for a symptom scale/item represents a high level of symptomatology/problems (Fayers P, 2001).

\subsection{Maximal strength training}

The MST group attended two supervised training sessions per week for

12 weeks. The training was carried at the Breast Surgery Department at the 
Oncology Centre of Latvia, Riga, Latvia. As for the testing, MST was performed as a dynamic leg press in the horizontal leg press apparatus using a $90^{\circ} \mathrm{knee-}$ joint angle. Following two warm-up sets, the patients performed 4 sets of 4 repetitions at $\sim 90 \%$ of 1 RM. Emphasis was put on slow velocity in the eccentric phase and maximal intended velocity in the concentric, contraction phase. A marked stop of $\sim 0.5$ seconds was applied between the eccentric and concentric contraction phases. Rest periods minimum of 3 minutes were used between sets. The load was increased by $2.5 \mathrm{~kg}$ when the patients were able to complete all sets. The patients were trained in groups of 3-5 individuals and all training sessions were supervised. A training session typically lasted for 20 minutes, and each time the patients attended training they were asked if they experienced MST-related discomfort, pain or other adverse events during or between the MST sessions, except the lifted loads feeling heavy when executed. The control group was instructed to perform 3 sets of 10 chair rises twice a week for 12 weeks. All patients were encouraged to maintain their typical level of physical activity during the study period. It was emphasized for both groups not to engage in additional exercise training during the intervention period. After the study, all patients (MST group and control group) received physical activity recommendations based on ACSM guidelines (Campbell, Winters-Stone et al., 2019).

\subsection{Statistical analysis}

Statistical analyses were performed using IBM SPSS (version 25), and figures were made using Graph Pad Prism software (version 8). Changes in dependent variables were examined using a repeated measure mixed ANOVA, with a group (control, MST) and time (pre, post) as factors. Significant interactions were followed up with independent sample t-tests for between-group differences and paired sample t-tests for within-group differences. Spearman's 
correlation was used to assess associations between pre- to post-test changes in $1 \mathrm{RM}$ and pre- to post-test changes in the walking economy, TTE, QoL and functional variables for combined groups. For categorical variables, $\chi^{2}$ or Fisher's Exact test was used to determine the difference between groups. The statistical level of significance was set at $\mathrm{P}<0.05$. Cohen's d: value effect $0.1-$ 0.2 small, $0.3-0.5$ medium, $0.6-0.8$ large, $0.9-1.10+$ extreme large. 


\section{Results}

55 of 57 initially scheduled patients completed the study, additional characteristics of patients who completed the study are presented at (Table 2.1.).

Table 2.1.

Patient characteristics and physical activity level at baseline

\begin{tabular}{|c|c|c|c|}
\hline & $\begin{array}{l}\text { MST group } \\
(n=27)\end{array}$ & $\begin{array}{l}\text { Control group } \\
(n=28)\end{array}$ & P-value \\
\hline Physical activity level (\%) & & & 0.59 \\
\hline Low - 3.3 METs & $22(82)$ & $21(75)$ & \\
\hline Moderate -4.0 METs & $3(11)$ & $6(21)$ & \\
\hline High - 8.0 METs & $2(7)$ & $1(4)$ & \\
\hline Strength training & 0 & 0 & $<0.99$ \\
\hline Smoking status (\%) & & & $<0.99$ \\
\hline Current & $3(11)$ & $3(10)$ & \\
\hline Former & $1(4)$ & $2(7)$ & \\
\hline Non-smoker & $23(85)$ & $23(83)$ & \\
\hline $\begin{array}{l}\text { Married, cohabiting or in a } \\
\text { relationship }(\%)\end{array}$ & $20(74)$ & $23(82)$ & 0.70 \\
\hline
\end{tabular}

Categorical variables are presented as $\mathrm{n}(\%)$. MST; maximal strength training, MET; metabolic equivalent. Physical activity level was assessed by applying the short form of the International Physical Activity Questionnaire short form.

\subsection{One-repetition maximum}

No between-group difference was observed in one-repetition maximum (1RM) at the pre-test $(\mathrm{P}=0.187)$, (Table 2.2.), (Figure 2.1.). 
Table 2.2.

Muscle strength of breast cancer patients before and after of control period and maximal strength training

\begin{tabular}{lllll}
\hline Variables & $\begin{array}{l}\text { Baseline } \\
\text { Mean } \pm \text { SD }\end{array}$ & $\begin{array}{l}\text { After 12 weeks } \\
\text { Mean } \pm \text { SD }\end{array}$ & $\begin{array}{l}\text { Estimated means } \\
\text { difference }(\mathbf{9 5 \%} \\
\text { CI) }\end{array}$ & $\begin{array}{l}\text { P-value and } \\
\text { Cohen's } d- \\
\text { value after } \\
\text { intervention }\end{array}$ \\
\hline $\begin{array}{l}\text { One repetition } \\
\text { maximum }(\mathbf{k g})\end{array}$ & $106.8 \pm 22.8$ & $127.2 \pm 26.4$ & $20.4(17.3$ to 23.6$)$ & $\mathbf{0 . 0 0 1} ;(0.9)$ \\
$\begin{array}{l}\text { Exercise } \\
\text { Control }\end{array}$ & $98.9 \pm 20.7$ & $89.9 \pm 20.9$ & $-8.9(-11.0$ to -6.9$)$ & $\mathbf{0 . 0 0 1} ;(0.5)$ \\
$\begin{array}{l}\text { P-value and } \\
\begin{array}{l}\text { Cohen's } d \text {-value } \\
\text { between the } \\
\text { groups }\end{array}\end{array}$ & $0.19 ;(0.3)$ & $\mathbf{0 . 0 0 1} ;(1.6)$ & & \\
\hline
\end{tabular}

Data are presented as mean \pm standard deviation.

- The MST group completed $23 \pm 1$ of 24 planned training sessions $96 \pm 4 \%$.

- The MST group increased $1 \mathrm{RM}$ by $20 \pm 8 \%$ ( $\mathrm{P}<0.001)$ from pre- to posttest.

- In contrast, $1 \mathrm{RM}$ decreased by $9 \pm 5 \%$ in the control group $(\mathrm{P}<0.001)$ from pre- to post-test.

- Resulting in 1RM being higher in the MST group compared to the control group at post-test $(\mathrm{P}<0.001)$, (Figure 2.1.). 


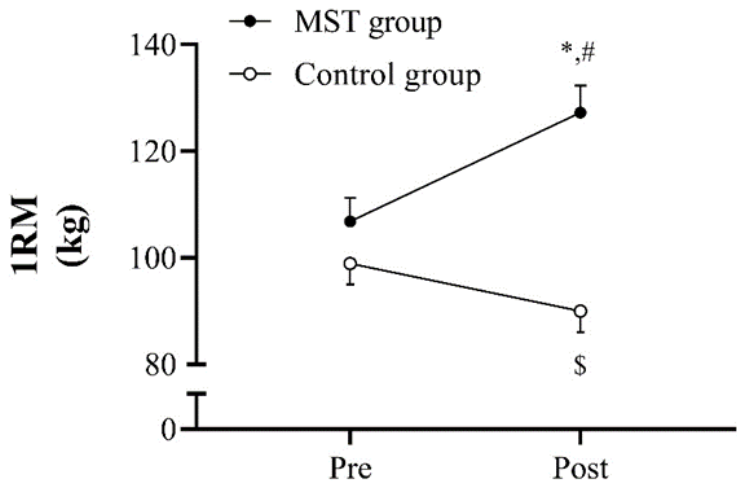

Figure 2.1. One repetition maximum (1RM) following 12 weeks of adjuvant therapy with and without maximal strength training (MST). Data are presented as mean \pm SE. * $p<0.05$, within-group increase from pre- to post-test. $\$ p<0.05$, within-group decrease from pre- to post-test. \# $p<0.05$, the difference between groups from pre- to post-test.

\subsection{Quadriceps femoris muscle mass}

- In the control group, Mqf decreased $(7 \pm 10 \%)$ from pre- to post-test $(\mathrm{P}<$ $0.001)$.

- No changes were found in the MST group, resulting in Mqf being higher in the MST group than the control group at post-test $(\mathrm{P}<0.001)$

- Changes in Mqf was associated with the training-induced changes in 1RM $(\mathrm{r}=0.45 ; \mathrm{P}<0.001)$, (Figure 2.2.). 

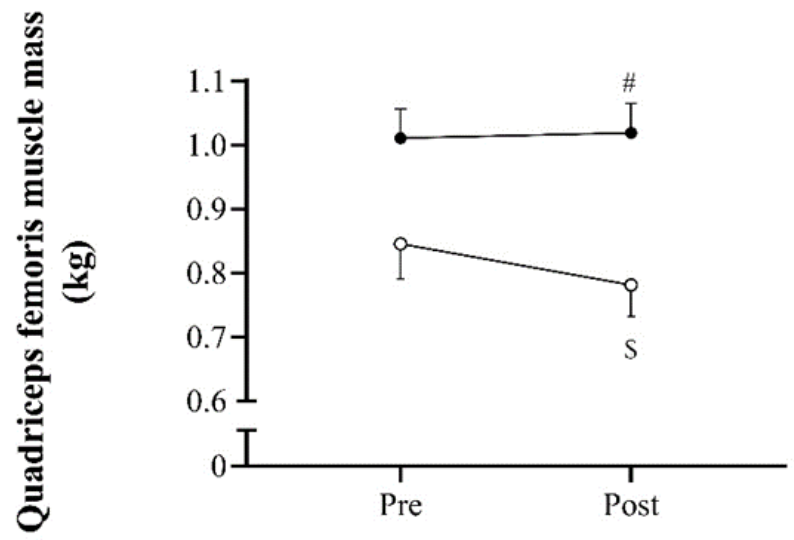

Figure 2.2. Quadriceps femoris muscle mass following 12 weeks of adjuvant therapy with and without maximal strength training (MST). Data are presented as mean \pm SE. $\$ p<0.05$, within-group decrease from pre- to post-test. \# $p<0.05$, the difference between groups from pre- to post-test.

\subsection{Aerobic endurance performance}

Walking economy and time to exhaustion are presented in (Table 2.3.) with the group - time interactions for the walking economy, the speed at exhaustion and inclination at exhaustion.

- In the MST group, improvements in 1RM were accompanied by the improved walking economy $(9 \pm 8 \%)$ and increased time to exhaustion during incremental walking $(9 \pm 8 \%$; both $\mathrm{P}<0.01)$.

- In contrast, the control group reduced walking economy $(4 \pm 4 \%)$ and time to exhaustion $(10 \pm 8 \%$; both $\mathrm{P}<0.01)$.

- Rating of perceived exertion, as can be seen from (Table 2.3.), rating of perceived exertion reported as Borg Score fairly well estimate the relative exercise intensity expressed as a percent of maximal heart rate. During the submaximal walking economy test, intensity corresponding to 40 Watts 
now requires significantly more exertion for the control group compared with the MST group, that perceived intensity as less strenuous. During the time to exhaustion test, patients were able to push themselves till the very hard feeling of exhaustion, both during pre-test and post-test.

Table 2.3.

Endurance performance before and after maximal strength training

\begin{tabular}{|c|c|c|c|c|}
\hline & Pre & Post & $\begin{array}{l}\text { P-value after } \\
\text { intervention }\end{array}$ & $\begin{array}{c}\text { Interactions } \\
\text { (Time x } \\
\text { Group) }\end{array}$ \\
\hline \multicolumn{5}{|l|}{ Walking economy } \\
\hline \multicolumn{5}{|l|}{ HR (beats $\cdot \mathrm{min}^{-1}$ ) } \\
\hline Exercise & $140 \pm 16$ & $128 \pm 15$ & $<0.001$ & $<0.001$ \\
\hline Control & $134 \pm 12$ & $149 \pm 12$ & 0.002 & \\
\hline$P$-value between groups & 0.150 & 0.009 & & \\
\hline \multicolumn{5}{|l|}{ RPE (6-20) } \\
\hline Exercise & $12 \pm 1$ & $10 \pm 2$ & $<0.001$ & $<0.001$ \\
\hline Control & $12 \pm 2$ & $13 \pm 1$ & 0.184 & \\
\hline$P$-value between groups & 0.289 & $<0.001$ & & \\
\hline \multicolumn{5}{|l|}{ Graded walking test } \\
\hline \multicolumn{5}{|l|}{$\mathrm{TE}(\mathrm{s})$} \\
\hline Exercise & $536 \pm 71$ & $571 \pm 68$ & $<\mathbf{0 . 0 0 1}$ & $<\mathbf{0 . 0 0 1}$ \\
\hline Control & $531 \pm 73$ & $476 \pm 63$ & $<0.001$ & \\
\hline$P$-value between groups & 0.814 & $<0.001$ & & \\
\hline \multicolumn{5}{|l|}{$\mathrm{HR}_{\max }\left(\right.$ beats $\left.\cdot \min ^{-1}\right)$} \\
\hline Exercise & $172 \pm 8$ & $172 \pm 7$ & $<0.99$ & 0.443 \\
\hline Control & $167 \pm 11$ & $166 \pm 11$ & 0.275 & \\
\hline$P$-value between groups & 0.042 & 0.013 & & \\
\hline \multicolumn{5}{|l|}{$\mathrm{E}_{\text {speed }}\left(\mathrm{km} \cdot \mathrm{h}^{-1}\right)$} \\
\hline Exercise & $4.8 \pm 0.4$ & $5.1 \pm 0.4$ & $<0.001$ & $<0.001$ \\
\hline Control & $4.8 \pm 0.5$ & $4.7 \pm 0.3$ & 0.002 & \\
\hline$P$-value between groups & 0.454 & 0.001 & & \\
\hline \multicolumn{5}{|l|}{$E_{\text {inclination }}(\%)$} \\
\hline Exercise & $11 \pm 1$ & $12 \pm 1$ & 0.009 & $<0.001$ \\
\hline Control & $11 \pm 1$ & $10 \pm 2$ & 0.003 & \\
\hline$P$-value between groups & 0.402 & 0.010 & & \\
\hline
\end{tabular}


Table 2.3. (Continued)

\begin{tabular}{lllll}
\hline & Pre & Post & $\begin{array}{l}\text { P-value after } \\
\text { intervention }\end{array}$ & $\begin{array}{c}\text { Interactions } \\
\text { (Time } \mathbf{x} \\
\text { Group) }\end{array}$ \\
\hline $\begin{array}{c}\text { RPE (6-20) } \\
\quad \text { Exercise }\end{array}$ & $17 \pm 1$ & $18 \pm 1$ & 0.120 & 0.475 \\
$\quad \begin{array}{l}\text { Control } \\
P \text { - value between groups }\end{array}$ & 0.975 & 0.372 & 0.563 & \\
\hline
\end{tabular}

$\overline{\text { Data are presented as mean } \pm \text { standard deviation. MST; maximal strength training, HR; }}$ heart rate, RPE; rating of perceived exertion, TE; time to exhaustion, $\mathrm{HR}_{\max }$; maximal heart rate, Espeed; treadmill speed at exhaustion, Einclination; treadmill inclination at exhaustion.

\subsection{Functional performance}

- At post-test, the MST group displayed improvements in all functional performance tests, the 6MWD improved by $(10 \pm 7 \%)$, chair rising performance by $(30 \pm 20 \%)$ and stair climbing performance by $(12 \pm 7 \%$; all $\mathrm{P}<0.001$ ), presented at (Figure 2.3.).

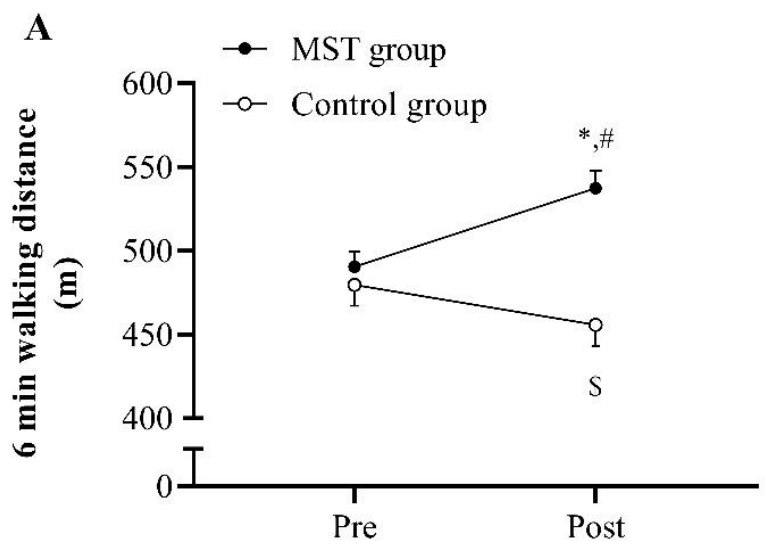


B

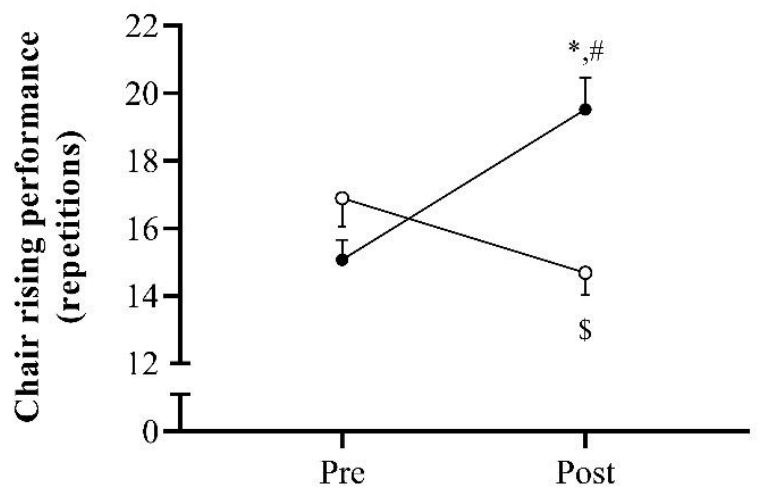

C

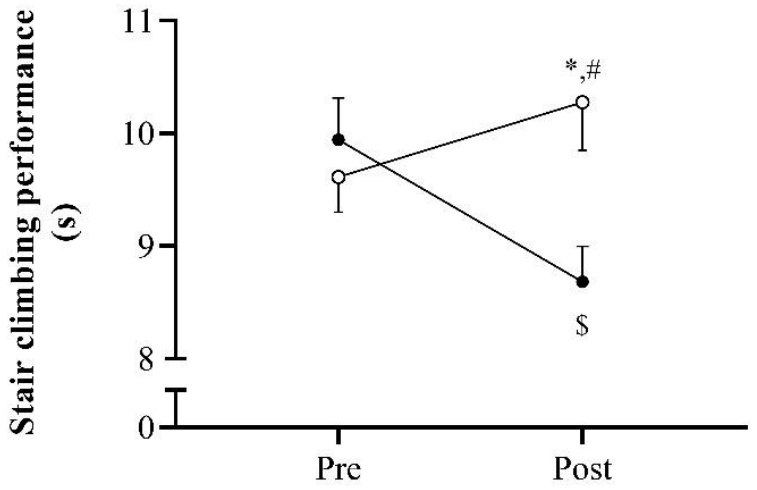

Figure 2.3. (A) 6MWD (m), (B) chair rising performance (repetitions), and (C) stair climbing performance (s) after 12 wk of adjuvant therapy with and without maximal strength training (MST). Data are presented as mean $\pm \mathrm{SE},{ }^{*} \mathbf{P}<\mathbf{0 . 0 5}$, increase within-group from pretest to posttest. ${ }^{\$} \mathbf{P}<0.05$, decrease within-group from pretest to posttest. ${ }^{\#} \mathbf{P}<0.05$ difference between groups from pretest to posttest. 
- Conversely, in the control group, reductions were found in the 6MWD (5 \pm $5 \%$ ), chair rising performance $(12 \pm 12 \%)$, and stair climbing performance $(6 \pm 8 \%$; all $\mathrm{P}<0.001)$.

- As a result, 6MWD $(\mathrm{P}<0.001)$, chair rising performance $(\mathrm{P}<0.001)$, and stair climbing performance $(\mathrm{P}=0.004)$ were different between groups at post-test.

- The change in 1RM correlated with the change in walking economy $(\mathrm{r}=0.754)$, time to exhaustion $(\mathrm{r}=0.793)$, six minutes walking distance $(\mathrm{r}=0.807)$, chair rising performance $(\mathrm{r}=0.808)$, and stair climbing performance $(\mathrm{r}=0.754$; all $\mathrm{P}<0.001)$, presented at (Figure 2.4.).

- MST group

A

- Control group

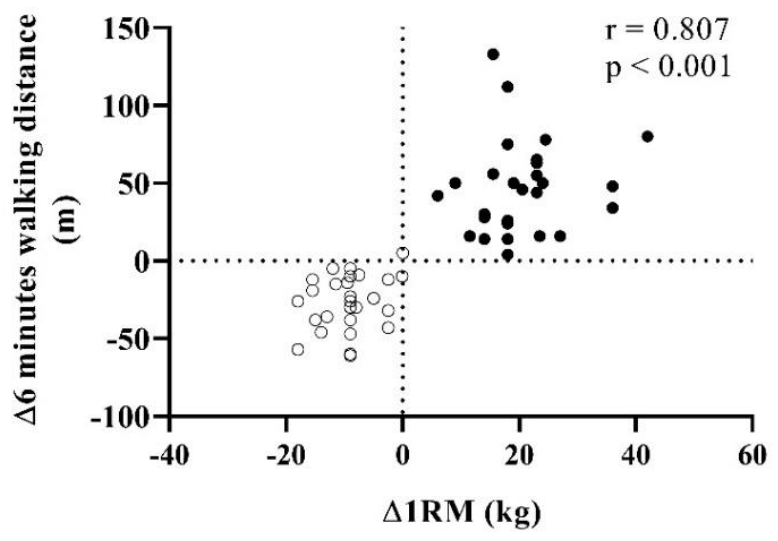




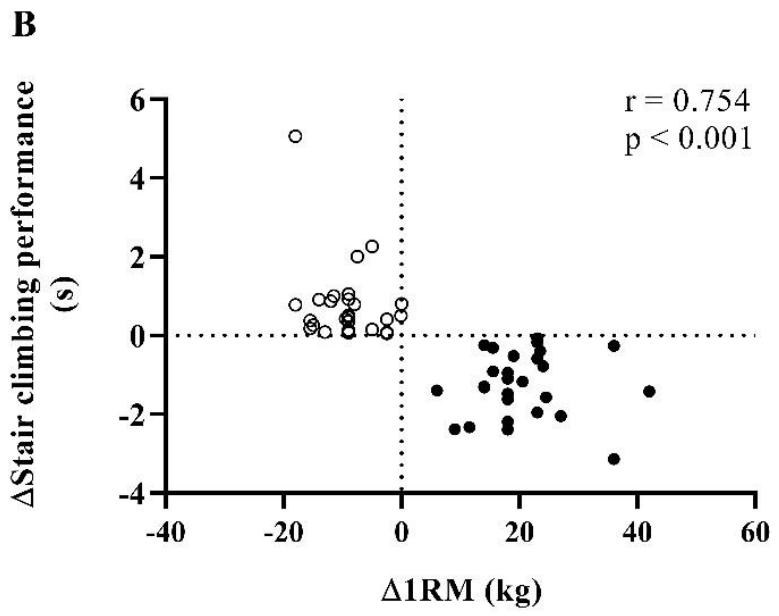

C

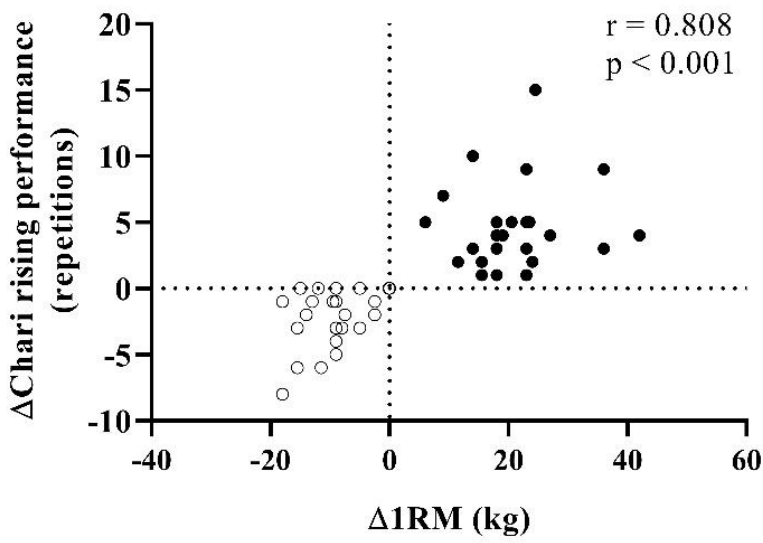


D

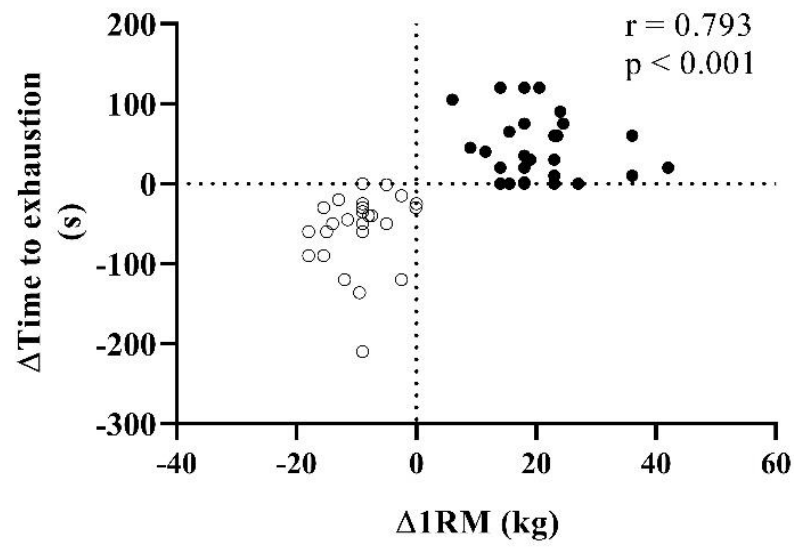

$\mathbf{E}$

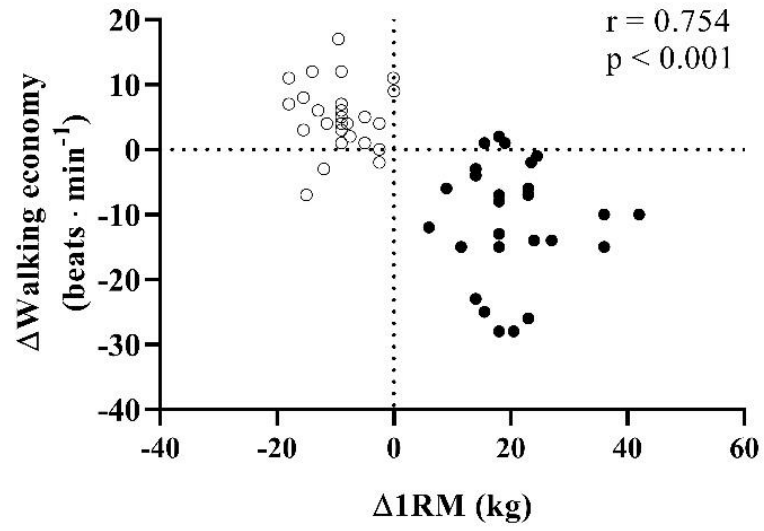

Figure 2.4. Associations between changes in maximal strength (leg press one-repetition maximum) and changes in (A) 6minutes walking distance, (B) stair climbing performance, (C) chair rising performance, (D) time to exhaustion during incremental walking and (E) walking work economy following 12 weeks of breast cancer adjuvant therapy with and without maximal strength training (MST). 


\subsection{Health-related quality of life}

Changes in Health-related quality of life were measured using The European Organisation for Research and Treatment of Cancer Core Quality of life Questionnaire-C30 (Table 2.4.) and additional Breast cancer module BR23 (Table 2.5.) for MST group and control group followed 12 weeks of the intervention period.

\section{The core questionnaire; QLQ-C30}

No significant differences in baseline values between the groups were observed $(\mathrm{p}>0.05)$, (Table 2.4.).

Global health status

- The Global health status/QoL (QoL) improved by 13\% for the MST group with a large effect $(\mathrm{P}=0.002, \mathrm{~d}=0.6)$, but no relevant changes were observed in the control group $(\mathrm{P}=0.44, \mathrm{~d}=0.2)$. The results obtained from the posttest revealed changes with extreme large effect size in QoL between the groups $(\mathrm{P}=0.002, \mathrm{~d}=0.9)$.

- The improvements in $1 \mathrm{RM}$ correlated with the change in QoL $(\mathrm{r}=0.60$; $\mathrm{P}<0.001$ ), (Figure 2.5.). 


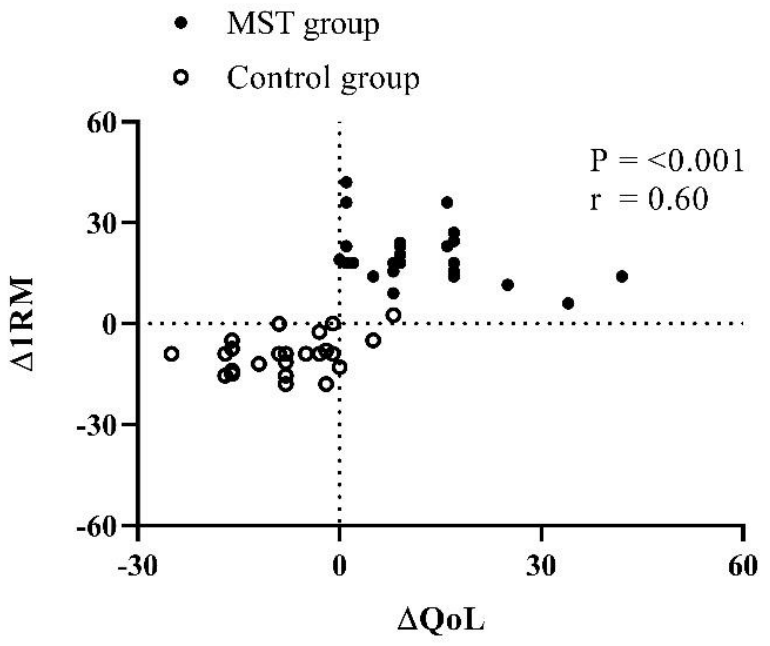

Figure 2.5. Correlation between changes in maximal strength (leg press one-repetition maximum 1RM) and changes in Global health status/QoL (QoL) following 12 weeks of breast cancer adjuvant therapy with and without maximal strength training (MST).

\section{Functional scales}

- Role functioning for MST group increased by $23 \%(\mathrm{P}=0.001, \mathrm{~d}=0.7)$, social functioning by $12 \%(\mathrm{P}=0.01, \mathrm{~d}=0.5)$, emotional functioning improved by $13 \%(\mathrm{P}=0.001, \mathrm{~d}=0.5)$, while emotional functioning decreased by $11 \%$ $(\mathrm{P}=0.02, \mathrm{~d}=0.4)$ in the control group.

- At post-test, differences with large effect size were observed between groups in emotional functioning $(\mathrm{P}=0.005, \mathrm{~d}=0.7)$ and social functioning $(\mathrm{P}=0.004, \mathrm{~d}=0.9)$.

- In other functional scales - physical functioning and cognitive functioning - no changes were observed within groups from pre to posttest, however, physical functioning was higher with extreme large effect 
size in the MST group compared to the control group after the intervention $(\mathrm{P}=0.003, \mathrm{~d}=0.9)$.

\section{Symptom scales}

Cancer-related fatigue (CRF) diminished by $24 \%(\mathrm{P}=0.03, \mathrm{~d}=0.6)$ in the MST group, while it became worse by $25 \%(\mathrm{P}=0.02, \mathrm{~d}=0.4)$ in the control group (Table 2.4.). Differences between groups after the post-test with a large effect in this variable size were observed $(\mathrm{P}=0.01, \mathrm{~d}=0.6)$.

Table 2.4.

\section{Changes in health related quality of life using the core questionnaire (QLQ-C30) before and after the intervention}

\begin{tabular}{|c|c|c|c|}
\hline Variables & $\begin{array}{l}\text { Baseline } \\
\text { Mean } \pm \text { SD }\end{array}$ & $\begin{array}{l}\text { After 12 } \\
\text { weeks } \\
\text { Mean } \pm \text { SD }\end{array}$ & $\begin{array}{l}P \text {-value and } \\
\text { Cohen's } d \\
\text { value after } \\
\text { intervention }\end{array}$ \\
\hline \multicolumn{4}{|l|}{ Global health status / QoL } \\
\hline Exercise & $67.2 \pm 15.6$ & $76.2 \pm 14.3$ & $\mathbf{0 . 0 0 2} ;(0.6)$ \\
\hline Control & $66.3 \pm 16.5$ & $63.5 \pm 14.7$ & $0.44 ;(0.2)$ \\
\hline $\begin{array}{l}P \text { value and Cohen's } d \text { value } \\
\text { between the groups }\end{array}$ & $0.84 ;(0.1)$ & $\mathbf{0 . 0 0 2} ;(0.9)$ & \\
\hline \multicolumn{4}{|l|}{ Functional scales } \\
\hline Exercise & $88.6 \pm 8.2$ & $90.6 \pm 6.4$ & $0.17 ;(0.3)$ \\
\hline Control & $84.2 \pm 14.6$ & $81.6 \pm 13.2$ & $\mathbf{0 . 0 7} ;(0.2)$ \\
\hline $\begin{array}{l}P \text { value and Cohen's d value } \\
\text { between the groups }\end{array}$ & $0.18 ;(0.3)$ & $\mathbf{0 . 0 0 3} ;(0.9)$ & \\
\hline \multicolumn{4}{|l|}{ Role functioning } \\
\hline Exercise & $70.0 \pm 26.7$ & $85.9 \pm 18.2$ & $\mathbf{0 . 0 0 1} ;(0.7)$ \\
\hline Control & $69.1 \pm 25.5$ & $77.0 \pm 19.5$ & $0.13 ;(0.4)$ \\
\hline $\begin{array}{l}P \text { value and Cohen's } d \text { value } \\
\text { between the groups }\end{array}$ & $0.89 ;(0.01)$ & $\mathbf{0 . 0 9} ;(0.01)$ & \\
\hline \multicolumn{4}{|l|}{ Emotional functioning } \\
\hline Exercise & $72.4 \pm 21.1$ & $82.1 \pm 18.8$ & $\mathbf{0 . 0 0 2} ;(0.5)$ \\
\hline Control & $74.4 \pm 23.9$ & $66.3 \pm 21.3$ & $0.02 ;(0.4)$ \\
\hline $\begin{array}{l}P \text { value and Cohen's } d \text { value } \\
\text { between the groups }\end{array}$ & $0.76 ;(0.1)$ & $\mathbf{0 . 0 0 5} ;(0.8)$ & \\
\hline
\end{tabular}


Table 2.4. (Continued)

\begin{tabular}{|c|c|c|c|}
\hline Variables & $\begin{array}{l}\text { Baseline } \\
\text { Mean } \pm \text { SD }\end{array}$ & $\begin{array}{l}\text { After 12 } \\
\text { weeks } \\
\text { Mean } \pm \text { SD }\end{array}$ & $\begin{array}{l}\text { P-value and } \\
\text { Cohen's d } \\
\text { value after } \\
\text { intervention } \\
\end{array}$ \\
\hline $\begin{array}{l}\text { Cognitive functioning } \\
\text { Exercise } \\
\text { Control } \\
P \text { value and Cohen's } d \text { value } \\
\text { between the groups }\end{array}$ & $\begin{array}{l}86.3 \pm 15.4 \\
86.2 \pm 18.2 \\
0.99 ;(0.1)\end{array}$ & $\begin{array}{l}87.0 \pm 14.1 \\
80.8 \pm 19.5 \\
0.19 ;(0.4)\end{array}$ & $\begin{array}{l}0.83 ;(0.1) \\
0.11 ;(0.3)\end{array}$ \\
\hline $\begin{array}{l}\text { Social functioning } \\
\text { Exercise } \\
\text { Control } \\
P \text { value and Cohen's } d \text { value } \\
\text { between the groups }\end{array}$ & $\begin{array}{l}76.4 \pm 24.1 \\
74.3 \pm 27.3 \\
0.76 ;(0.1)\end{array}$ & $\begin{array}{l}85.7 \pm 16.4 \\
70.2 \pm 20.9 \\
\mathbf{0 . 0 0 4} ;(0.8)\end{array}$ & $\begin{array}{l}\mathbf{0 . 0 1} ;(0.5) \\
0.29 ;(0.2)\end{array}$ \\
\hline $\begin{array}{l}\text { Symptom scales } \\
\text { Fatigue } \\
\text { Exercise } \\
\text { Control } \\
P \text { value and Cohen's } d \text { value } \\
\text { between the groups }\end{array}$ & $\begin{array}{l}33.5 \pm 17.1 \\
29.5 \pm 18.5 \\
0.41 ;(0.2)\end{array}$ & $\begin{array}{l}25.5 \pm 15.5 \\
36.8 \pm 16.7 \\
\mathbf{0 . 0 1} ;(0.6)\end{array}$ & $\begin{array}{l}\mathbf{0 . 0 3} ;(0.6) \\
0.16 ;(0.4)\end{array}$ \\
\hline
\end{tabular}

Data are presented as mean \pm standard deviation.

\section{Breast cancer module QLQ-BR23}

Changes in the EORTC QLQBR23 supplementary model are listed in (Table 2.5.).

\section{Functional scales}

- A decrease in body image with medium effect size $(\mathrm{P}=0.05, \mathrm{~d}=4)$ was noticed in the control group at the post-test. This variable did not alter in the MST group but showed a medium effect size $(\mathrm{P}=0.2 \mathrm{~d}=0.3)$.

\section{Symptom scales}

- Systemic therapy side effects worsen with the large effect size for the control group $(\mathrm{P}=0.001, \mathrm{~d}=0.8)$, while there were no considerable changes 
for the MST group, indicating medium effect size $(\mathrm{P}=0.4, \mathrm{~d}=0.3)$. Differences with large effect size $(\mathrm{P}=0.04, \mathrm{~d}=0.5)$ were observed between the groups at post-test.

Table 2.5.

Changes in health related quality of life using Breast cancer module: QLQ-BR23 before and after the intervention

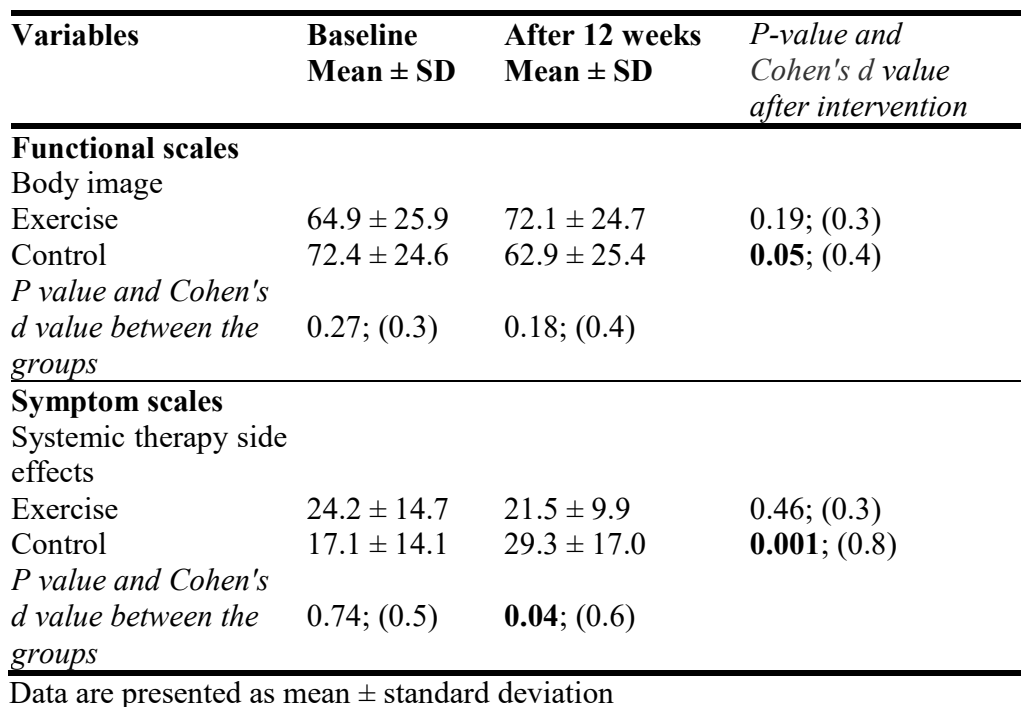

Data are presented as mean \pm standard deviation 


\section{Discussion}

Adjuvant BC therapy is associated with reduced muscle strength, muscle mass and amount of physical activity (Irwin et al., 2003), (Klassen et al., 2017), (Mijwel et al., 2018c), contributing to the reduced overall HRQoL (Mijwel et al., 2018a). Despite the well-documented effectiveness of strength training to improve these factors in other patient groups, evidence of the strength training, particularly applying higher intensity, in the important initial phase of $\mathrm{BC}$ treatment is very limited.

Therefore, the current thesis sought to investigate the effect of strength training in functionally relevant lower extremities, performed with high loads ( $~ 90 \% 1 \mathrm{RM})$ and few repetitions (4), in newly diagnosed BC patients undergoing adjuvant therapy. The major findings were that three months of MST yielded large improvements in lower extremity maximal muscle strength, walking economy and functional performance, and maintained muscle mass. Additionally, improved strength contributed to increased HRQoL, and improved role functioning, emotional functioning, social functioning, simultaneously reducing the sense of CRF. Importantly, improvements in body image and reduction in side effects experienced during treatment showed significant changes after the intervention period. Conversely, patients assigned to the control group receiving prescribed treatment alone without any strength training displayed reductions in all assessed variables. The majority of the patients were not physically active starting adjuvant treatment, thus it has been shown that lower physical activity level has the potential to increase the risk of being diagnosed with cancer (McTiernan et al., 2019). The results of the current study add to a growing body of evidence supporting the inclusion of structured strength exercise prescription and advocate that lower extremity MST should be considered as part of $\mathrm{BC}$ management post-surgery, preferably starting before 
initiation of adjuvant chemotherapy to maintain, or even improve, physical and mental health.

\subsection{Muscle strength following maximal strength training}

Strength training has the purpose of inducing neural and muscular adaptations. Strength training programs for BC patients vary considerably in training volume (the amount of work done: including repetitions per exercise and the total amount of sets per training session), frequency (how often certain exercise is performed/practiced or certain muscle trained) and intensity (percentage of 1RM of weight that has been used during exercise) (al-Majid and McCarthy, 2001), (Campbell et al., 2012).

Most of the strength training interventions in oncology settings apply low to moderate training intensities $<75 \%$ of $1 \mathrm{RM}$, using $1-3$ sets and performing $\geq 8$ repetitions. Typically training interventions last 4-weeks to even 12 months, carried out in clinical setting or home-based training programs, performing an exercise with a slow movement in concentric action, and initiation of the training commonly starts after completion of primary treatment (Wernbom et al., 2007), (Schmitz et al., 2010), (Hagstrom et al., 2019). Therefore, a need to expand knowledge and contribute to the exercise oncology field, well-defined strength training methods with higher strength training intensity are gaining recognition. To our knowledge, the present study is the first to test the effects of high-intensity strength training in $\mathrm{BC}$ patients receiving adjuvant therapy.

In the present study, the control group that received standard adjuvant treatment alone without strength training displayed a $9 \%$ decrease in leg press maximal muscle strength, apparent after only 12 weeks of adjuvant therapy, corresponds to more than one decade of typical aging (Lindle et al., 1997), whereas patients in the MST group performed strength training two times a week had $\sim 30 \%$ higher maximal muscle strength after three months than the control 
group. This MST-induced effect is similar to what has been observed after a comparable volume of leg press MST in healthy individuals (Hoff et al., 2002) and other patient populations (Hoff et al., 2007), (Wang et al., 2010), (Helgerud et al., 2011) where leg press MST has been examined in COPD and peripheral arterial disease patients (PAD). Even though the pathology is different, COPD, $\mathrm{PAD}$ and $\mathrm{BC}$ patients share the condition of being untrained and with lower physical capacities. The strength improvements in the COPD and PAD patients were similar to the improvements observed in the present study with dynamic 1RM. It is striking that MST seems to cause similar improvements in strength across age, level of physical capacities and patient populations when the intensity is kept constant. Importantly, the $\sim 20 \mathrm{~kg}$ improvement in leg press $1 \mathrm{RM}$ for the MST group in the current study is about 2.5 times larger compared to the $\sim 8 \mathrm{~kg}$ $1 \mathrm{RM}$ increase observed in a previous study were the patients exercised three times a week with an intensity corresponding to $60-70 \%$ of 1RM (Courneya et al., 2007b).

Several mechanisms might explain large strength gains despite receiving adjuvant chemotherapy. The repeated, regular, episodic bouts of muscle contraction associated with strength training stimulate numerous physiological adaptations, altering the phenotype of skeletal muscle; including changes in the contractile apparatus, mitochondrial function, metabolic regulation and intracellular signaling, amount of contractile protein and stiffness of the connective tissue (Wernbom et al., 2007). The adaptations to strength training are generally observed after 8 to 12 weeks (Folland and Williams, 2007), which may result in an increase in muscle size by increasing cross-sectional area, neural adaptations (motor output) and improved muscle strength (maximal force production). Adaptations evident within the neuromuscular system have centered on increases in motor learning through the nervous system and increased maximal muscle activation by motor unit synchronization, muscle recruitment 
and increased neural activation (Endo et al., 2020). All of these adaptations play important role in strength increase following effective strength training.

Typically MST has been shown to improve both maximal strength and RFD, generally, RFD improves ranging from $26 \%$ to $60 \%$, and is important in functional performance (Heggelund et al., 2013), (Unhjem et al., 2016). Although not measured in the present study, similar improvements in RFD might have been gained for BC that participated in the MST. This is also supported by improved walking economy, which has been mainly attributed to improved RFD (Støren et al., 2008). Contrary, the control group performing chair rises three times per week did not reach the required intensity, thus not ensuring enough stimulus to excite motor units, and muscle strength decreased were accompanied with reduced walking economy and functional performance.

Reduce muscular strength and RFD have been associated with a higher risk of falls and fractures (Moreland et al., 2004). Increased age, anti-cancer treatment side effects and decreased bone density (Winters-Stone et al., 2013) along with the reduced RFD, put BC patients at higher risk of falls and impaired daily functions.

\subsection{Changes in muscle mass}

Muscle atrophy or cancer-related muscle wasting also known as cachexia may be triggered as a consequence of many different physiological and pathological processes. Cachexia is the cause of death for approximately 2 million people worldwide and severely reduces HRQoL (Burckart et al., 2010), which is a prevalent side-effect, often occurs as a consequence of anti-cancer treatment and is indicative of worse outcomes and poor participation in daily activities in cancer patients (Mazzuca et al., 2018). Cachexia is associated with approximately $80 \%$ of severe cancer cases and it is responsible for more than $30 \%$ of all cancer-related deaths (Isaac, Tan et al., 2015). 
The molecular mechanisms underlying cancer-related muscle wasting have not been fully elucidated. Available evidence suggests that a notable role is played by increased muscle protein degradation and impaired muscle protein synthesis and insufficient myogenesis. Multiple factors appear to contribute to alterations in muscle wasting, such as several pro-inflammatory cytokines that have been produced by some of the tumor cells: tumor necrosis factor-alpha (TNF- $\alpha$ ), interleukin 1 (IL-1 $\alpha, \beta$ ), interleukin-6 (IL-6), interferon-gamma (IFN- $\gamma$ ), leukemia inhibitory factor (LIF), ciliary neurotrophic factor (SNTF) (Schneider, Hsieh et al., 2007), (Battaglini et al., 2012). These inflammatory mediators and tumor products limit anabolism and increased catabolism that contributes to loss of the lean muscle mass that occurs due to decline in protein synthesis and increased protein degradation (Argiles, Costelli et al., 1999), (Yakovenko et al., 2018) if unchecked, these physiological responses/ adaptations lead to a gradual reduction in functionality and thus worse HRQoL. Also, alterations in energy metabolism involving mitochondrial dysfunction have been linked to the cancer-related muscle wasting process (Johns et al., 2013). For example, while the loss of contractile proteins predominantly affects the type II fast fibers during aging or cancer cachexia, causing a rise to a higher proportion of slow type I versus fast fibers (Fanzani et al., 2012). These alterations in combination with anti-cancer treatment and absence of strength training for the control group lead to significantly reduced Mqf by $(7 \pm 10 \%)$.

Researchers for several years have taken this integrative physiology approach in an attempt to examine the influence of exercise training on mitigating the cachectic effects in cancer patients (Battaglini et al., 2007), (Lira et al., 2011). Importantly the positive influence of physical exercise on protein synthesis in skeletal muscle through an up-regulation of anti-inflammatory cytokines: the interleukin-1 receptor antagonist (IL-1RA), interleukin 4 (IL-4), interleukin 10 (IL-10), interleukin 15 (IL-15), soluble tumor necrosis factor 
receptors (sTNFR), soluble IL-6 receptor (sIL6R) and acceleration of myoplasticity events (i.e., protein synthesis) within the skeletal muscle have been recognized (Kim et al., 2015), (Suzuki, 2018). Our study supports and demonstrates that $\mathrm{BC}$ patients can engage in regular strength training and that physical exercise have the potential to shift the balance of protein turnover towards an anabolic vs. catabolic state (Montalvo et al., 2018). That is, the appropriate amount of strength training facilitates muscle mass retention or even hypertrophy.

However, only a few studies have been able to demonstrate the effect of strength training on muscle mass during anti-cancer treatment (Christensen et al., 2018). Importantly, muscular adaptations to training, first occur at the neural level, before morphological changes, which are dependent on protein synthesis and myofibrillar transformation, thus, taking a relatively longer adaption period (Folland and Williams, 2007). As previously described and typically observed for $\mathrm{BC}$ patients following anti-cancer treatment, the control group in the present study, displayed reductions in Mqf, indicating that muscular alterations contributed to the reduction in lower extremity maximal muscle strength. Indeed, our results revealed a tendency for alterations in Mqf to be associated with changes in lower extremity maximal muscle strength. In this perspective, the length of most strength exercise-trials for cancer patients are relatively short $(<3$ months), suggesting that while the time for morphological adaptations might be too limited to observe large-enough adaptations, but might be adequate for neural adaptations (Egan and Zierath, 2013). Although MST primary is tailored to induce neural adaptations and has a relatively low metabolic stress, it was effective to maintain Mqf in the current study for the MST group. This may be unsurprising considering a recent study, documenting that MST led to similar improvements in muscle morphology as what is seen following conventional (hypertrophy) training with 10-12 repetitions of moderate-intensity (70-75\% of 
1RM) in older adults (Wang et al., 2017). Our results show and support previous findings that MST primary is tailored to increase the muscle strength through neural mechanisms, importantly that muscle mass can be maintained during adjuvant treatment, emphasizing that $\mathrm{BC}$ can experience both neural and muscle morphological adaptations during adjuvant chemotherapy.

The absence of strength training led to reduced muscle mass in the control group with a Mqf decrease $(7 \pm 10 \%)$ from pre-to post-test $(\mathrm{p}<0.001)$. Emerging evidence supports that chemotherapeutics promote a reduction of muscle fiber size, causing severe depletion of skeletal muscle (sarcopenia) (Guigni et al., 2018). Depletion of muscle mass can lead to chemotherapy toxicity, which in turn may necessitate dose reduction or delayed administration (Prado et al., 2011). Indeed, it has been an important field of interest that patients who continue to be active during anti-cancer treatment and include strength training in their weekly routine can tolerate and enhance treatment efficacy and regain physical function much faster after treatment is completed (Segal et al., 2003), (Campbell et al., 2012), (Courneya et al., 2014), further supporting adding strength training during anti-cancer treatment. Patients diagnosed with $\mathrm{BC}$ often reduce daily physical activity, due to adverse effects like pain, physical weakness or chemotherapy-induced toxicity, also lack information, dialogue with physicians and encouragement to stay physically active during treatment, augment effects of inactivity (Christensen et al., 2014).

Our results further support that incorporation of strength training as a part of the therapeutic regime of cancer treatment can result in skeletal muscle protein synthesis, thus potentially maintaining muscle mass.

\subsection{Functional performance}

The present study highlights that MST improved functional performance, measured as stair climbing, sit to stand test and 6MWD. Again, a reduction in 
functional performance was observed in the control group in all measured functional tests. In combination, these findings indicate that the loss of muscle strength and mass during anti-cancer treatment is reflected in daily functional tasks, thus potentially having a large negative impact in HRQoL. Since the majority of weight-bearing activities are performed using the legs, strength training of the lower extremities may especially be an advantageous investment for the $\mathrm{BC}$ patients during anti-cancer treatment. For this purpose, leg press exercises, tasking the entire stretch apparatus may be a simple and effective strategy to improve the strength of important weight-bearing muscle groups.

\subsection{Maximal strength training improves walking economy}

After the intervention period walking economy improved the following 24 sessions of MST, by reduced heart rate during the submaximal walking economy test. The increased strength in $\mathrm{BC}$ patients led to improved aerobic endurance performance, by improving one of the main components; walking economy.

Several previous investigations have found MST to improve the work economy (Barrett-O'Keefe et al., 2012), (Wang et al., 2017), (Berg et al., 2018) and our study supports these findings adding that MST can effectively improve work economy measured during submaximal walking also for $\mathrm{BC}$ patients. Importantly that training compliance also was high in the current study, indicating that MST appears to be tolerable and feasible. Furthermore, in the present study, the improved walking economy correlated positively with improved muscle strength. This is in accordance with observations from Wang et al., (Wang et al., 2010), strengthening our assumption that the walking economy improvements were indeed related to the improved muscle strength.

The ability to sustain a selected work rate over a longer duration is important in daily life. As most activities in everyday life are carried out at light 
to moderate intensities, the $\mathrm{VO}_{2 \max }$ is rarely required (Støren et al., 2008). However, with declining $\mathrm{VO}_{2 \max }$ as a result of inactivity or disease, these chores would become increasingly difficult, or the intensity at which they were conducted would need to be reduced (Støren et al., 2008). Also, the absolute metabolic cost of everyday tasks is increased in several patient groups and with aging (Knaggs et al., 2011), further contributing to CRF.

Improvements in the walking economy contributed along with the other measures of physical function (6MWD; stair climbing; sit to stand; time to exhaustion) to an overall consideration that $\mathrm{BC}$ patients that had trained MST not only were able to avoid the typical reduction in daily function but were able to improve their performance correspondingly as is seen in healthy.

Contrary, the control group reduced the walking economy. It has been reported that neural mechanisms are responsible for early strength loss to muscle unloading. Indeed, a study by Deschenes et al. (2002) showed that after 2 weeks of right leg immobilization in a lightweight orthopedic knee brace to six male and four female college students decreased strength by $10 \%$, the velocity of peak torque decrease $17 \%$ in quadriceps muscle evaluated by electromyography recordings, muscle biopsy and total work performed. Results confirm that the loss of strength can primarily be attributed to a decreased capacity of the nervous system to excite the muscle (Deschenes et al., 2002).

Alterations in muscle resulting from reduced levels of physical activity may also contribute to a decrease in muscle endurance. These alterations reduce blood supply to less active muscles that leads to reduced capillary density, which impairs glucose transport and substrate availability, lower mitochondrial density and decreased oxidative enzyme activity, these reverse changes also reduce muscle ability to generate force (Thompson, 2002). Inverse adaptations to inactivity occur fast, and during the first week of immobilization muscle strength is reported to decline by approximately $4 \%$ each day (Suetta et al., 2004). 
Furthermore, it has been reported that muscle strength reduces 25 to $30 \%$ after 6 weeks of bed rest (Berg et al., 1997). Work economy is a major determinant of aerobic endurance performance. In real life, these performances may range from professional competitions and daily activities in patients with reduced physical capacities. In cancer patients work economy, more likely is at a level that challenges the performance of daily activities and may lead to reduced HRQoL. This study advocates MST using heavy loads and explosive movement in concentric action to improve the walking economy. After MST training walking economy improved by $\sim 9 \%$. In other words, a person now has the ability to perform more walking or to perform the same amount of work with reduced effort as observed in the present study, were walking at 40 Watts now required less energy. Opposite, 4\% reduced walking economy would likely have significant practical implications for control group.

\subsection{Tolerance of the high-intensity program}

Importantly, while MST may be considered strenuous, the $96 \%$ completion rate in the present study indicates that $\mathrm{BC}$ patients are, despite suffering adverse side effects of early phase adjuvant therapy, capable of performing strength training of the lower extremities with a targeted intensity $\sim 90 \%$ of $1 \mathrm{RM}$. Furthermore, the intervention was completed without any reported difficulties or injuries, indicating that the feasibility and safety of leg press MST during BC treatment should be considered satisfactory.

Of notice, it is only the concentric phase of movement during MST that is carried out with high intensity. The eccentric phase, which is more associated with muscle soreness and microdamage to the muscle (Toien et al., 2018), is carried out in a slow and controlled fashion. This is a likely reason why MST may be safely performed, as the high impact force associated with eccentric muscle action is avoided (Toien et al., 2018). Importantly, again, the concentric 
phase may preferably be performed with maximal intended velocity, to maximize neural stimulation (Behm and Sale, 1993). It is important aspect, as included patients in the present study are not considered well trained, therefore such methodology is safe and also effective for untrained individuals.

The targeted training intensity was met during all training sessions, and the sessions were also executed following the protocol. Included patients completed the study, and except for the repeated lifts typically being perceived as heavy, no patients reported MST-related adverse events during or between the testing or training procedures.

\subsection{Health-related quality of life}

HRQoL is part of objective quality of life and attributes to components of quality of life that center upon or are directly and indirectly affected by health condition (treatment side effects, physical, cognitive, emotional and social functioning, etc.) and as such HRQoL overlaps with the concept of health status (Karimi and Brazier, 2016). HRQoL is persons perceived physical, mental, social and functional health that is integrated these different domains in a common score, thus the universal goal for exercise trials in oncology seems to be focused on different physiological outcomes, to improve persons HRQoL.

Results in the present study show that 12 weeks of MST contributed to improved Global health status/QoL (QoL) by 13\% for the MST group, but no relevant changes were observed in the control group. Importantly, that intervention period induced improvements in role functioning by $23 \%$, emotional functioning by $13 \%$, social functioning by $12 \%$, simultaneously reducing the sense of CRF by $24 \%$ for the MST group. Thus, the benefit of strength training on fatigue appears to be not only statistically significant but also clinically relevant, as many $\mathrm{BC}$ patients experience fatigue as the most distressing side effect of chemotherapy (Berger et al., 2012). 
Similar to our findings, a trial was done by van Waart et al., (van Waart et al., 2015b) who included moderate to high-intensity aerobic endurance exercise and progressive strength exercise demonstrated that a combined exercise program was effective in counteracting CRF. In contrast, another trial by Mutrie et al., (Mutrie et al., 2007) showed no difference in CRF between participants performing combined aerobic endurance and strength exercises versus a control group at moderate-intensity, concluding that higher intensity/load was required to counteract increases in CRF and that multimodality of exercise may interfere with typical physiological adaptions from strength training alone. As our study investigated strength training alone without aerobic endurance exercise, therefore our results suggest that MST is an effective type of exercise, likely reducing fatigue with maintained muscle mass and improved physical functioning.

Noteworthy, the control group was not able to counteract a decrease in CRF following the intervention period, CRF worsened by $25 \%$. This indicates how severely disease and treatment without strength training impacts productivity tasks, leisure-time activities, family life and relationships with friends, all of these socially and emotionally important activities now would demand more energy. It seems that intensity is important not only to improve CRF but also to improve HRQoL. In the study by Courneya et al., (Courneya et al., 2007b) a multimodal training intervention did improve physical capacities but did not improve HRQoL, elucidating that strength training with and intensity (60-70\% of estimated 1RM) was not sufficient, and 70\% adherence of training sessions, have reduced total training volume. In contrast, $96 \%$ adherence rate in our study far exceeds the typically observed exercise trial adherence rate (Rejeski et al., 2007), this supports that high intensity indicates large strength gains and has substantially improved CRF, and HRQoL, despite the continuation of adjuvant anti-cancer therapy. In our study, BC patients continued MST with 
excellent adherence. Additionally, MST was initialized as early as possible, and before receiving the first chemotherapy session patients were familiar with training and already got initial strength improvements that kept them regularly to attend MST.

To our knowledge, this is the first trial to demonstrate the effects of MST on the role, social and emotional functioning in patients with $\mathrm{BC}$ during chemotherapy as observed from EORTC QLQ-C30 questionnaire. Our findings might be explained that being involved in a supervised exercise program can improve both role and emotional functioning, and such positive interaction might potently give noticeable improvements (McAuley et al., 2000). In our study, typically training was carried out in small groups of 3-5 patients, thus factors such as social support from the training pears, talking to other cancer patients, attention from an exercise physiologist, traveling to an exercise facility twice a week, and having a positive attitude by becoming proactive, may give an additional role for observed improvements. An increased level of self-efficacy has been suggested as a possible mechanism for improved emotional functioning in the elderly engaged in exercise (McAuley et al., 2000), which in our study may be linked to feelings of being able to carry out the MST and continue to carry out daily activities. Also, results from the EORTC QLQ-BR23 questionnaire reveal that systemic therapy side effects and body image worsen for the control group, whiles changes in these scales were mitigated for the MST group.

A cancer diagnosis is an especially challenging period for a person, MST has shown to be an effective method and contribute to improve HRQoL and reduce $\mathrm{CRF}$ for $\mathrm{BC}$ during early anti-cancer therapy. Although the guidelines of the American College of Sports Medicine and the American Cancer Society include strength training in exercise recommendations, predominantly exercise programs focus on aerobic endurance exercise. Therefore, our results will 
support raising awareness that strength training is effective and important in addition to aerobic endurance exercises. Importantly, our results support that MST works effectively not only on the physical aspect but also on the psychosocial aspect, thus positively influencing HRQoL.

\subsection{Strengths and limitations of the study}

Few studies have investigated the effects of strength training in the initial phase of $\mathrm{BC}$ treatment. A strength of the present study is the application of effective high-intensity strength training of functionally relevant muscle groups of the lower extremities. MST is time- and cost-efficient, demanding less than an hour of training per week, and patients may train in groups of 3-5 individuals per training apparatus during the same training session. Despite adverse early phase side effects of adjuvant therapy, the patients had a completion rate of $96 \%$, suggesting leg press MST to be a feasible exercise modality in this critical phase of BC treatment. Importantly, the strength training was also carried out without any observed injuries during the training period. Ultimately, the major strength in the current study was that the large improvements in lower extremity muscle strength were strongly associated with improvements in the patient's functional performance and also reduced CRF and improved HRQoL.

A limitation of the current study is the lack of measurements of neural and muscular components. This may have provided important information about the origin of the strength training-induced improvements, and if certain components of adjuvant therapy possibly affected some factors more than others. As BC patients may suffer attenuated bone health, it would also have been beneficial to include musculoskeletal measurements. Increased lower extremity muscle strength has previously been documented to result in enhanced bone formation and bone mineral density (Nygard et al., 2018), and it would have been of great value to investigate if this was also the case in our study. Finally, the 
relatively short duration of the study also represents a limitation, as information on long-term effects would have provided a better understanding of the role of exercise in breast cancer treatment and 5-year survival rate.

\subsection{Clinical implications for cancer rehabilitation}

The present study demonstrates the importance of counteracting the detrimental effects of adjuvant BC therapy on neuromuscular function. Indeed, while patients commencing leg press MST improved lower extremity maximal muscle strength, walking economy, functional performance, maintained muscle mass and improved HRQoL, the control group was subject to reductions in all these variables. Notably, 20 minutes of leg press MST 2 times per week was sufficient to gain lower extremity muscle strength and functionality. Only one exercise, dynamic leg press, was performed. Although it would be beneficial to include strength training of other muscle groups, the lower extremities should be prioritized due to their weight-bearing function. Taken together, the findings in the current study certainly support previous suggestions of implementation of strength training in adjuvant $\mathrm{BC}$ treatment and extend recommendations to include effective high-intensity MST of the lower extremities. However, when higher training intensities are applied, supervision of trained medical personal should be mandatory to avoid the risk of injuries. Strength training with progression should be accessible and implemented as soon as possible following the $\mathrm{BC}$ diagnosis, to maintain or even improves HRQoL. 


\section{Conclusion}

1. The present study showed that three months of leg press maximal strength training was an effective, safe and feasible method for improving maximal muscle strength during adjuvant breast cancer treatment.

2. Starting a strength training early during breast cancer treatment may prevent impaired muscle mass, maximal strength training ensured sufficient stimulus to maintain muscle mass for breast cancer patients during adjuvant therapy.

3. Improved lower extremity maximal muscle strength in breast cancer patients receiving adjuvant treatment was associated with improvements in the aerobic endurance capacity, by improving walking economy.

4. Maximal strength training on functionally relevant lower extremities improved functional performance.

5. Maximal strength training contributed to improved health-related quality of life, by reducing the sense of fatigue, improving global health status, social factors and lighting treatment side effects.

These results advocate that lower extremity high-intensity strength training should be considered a part of $\mathrm{BC}$ treatment to not only counteract the typically observed decline in lower extremity muscle strength but also to improve physical health, functionality and HRQoL from the time of diagnosis. 


\section{List of publications}

\section{List of original articles}

\section{Article I}

1. Heavy resistance training in breast cancer patients undergoing adjuvant therapy.

Ceseiko, R., Thomsen, S. N., Tomsone, S., Eglitis, J., Vetra, A., Srebnijs, A., Timofejevs, M., Purmalis, E., Wang, E. (2020). Heavy Resistance Training in Breast Cancer Patients Undergoing Adjuvant Therapy. Medicine and Science in Sports and Exercise, 2020;52(6):1239-1247.

\section{Article II}

2. The impact of maximal strength training on quality of life among women with breast cancer undergoing treatment.

Ceseiko, R., Eglitis, J., Srebnijs, A., Timofejevs, M., Purmalis, E., Erts, R., Vetra, A., Tomsone, S. (2019). The impact of maximal strength training on quality of life among women with breast cancer undergoing treatment. Experimental Oncology, 41(2), 166-172.

\section{Abstracts and presentations at the international conferences}

1. Ceseiko, R. (2017). 84P - Effective strength training for breast cancer patients: a literature review. Annals of Oncology, 28, x23. doi:https://doi.org/10.1093/annonc/mdx655.026. ESMO Asia 2017 Congress, Singapore, Singapore, 17/11/2017-19/11/2017 (Poster presentation). 
2. Ceseiko, R., Tomsone, S., Srebnijs, A., Vetra, A., Timofejevs, M., Purmalis, E. \& Eglitis, J. (2018). Maximal Strength Training for Breast Cancer Patients Undergoing Adjuvant Treatment. Journal of Global Oncology, 4(Supplement 2), 102s-102s. doi:10.1200/jgo.18.29400. World Cancer Congress held in Kuala Lumpur, Malaysia from 1 - 4 October 2018 (Oral presentation).

\section{Abstracts and presentations in local conferences in Latvia}

1. Cešeiko, R., Eglītis, J., Vētra, A., Tomsone, S. Efektīvas spēka treniņa metodes krūts vēža pacientēm: literatūras pārskats. Rīgas Stradiṇa universitātes 2018. gada zinātniskā konference, Rīga, Latvija, tēžu grāmata: 119 (Oral presentation).

2. Cešeiko, R., Eglītis, J., Srebnijs, A., Timofejevs, M., Purmalis, E., Tomsone, S. Krūts vēža slimnieču aerobās spējas pirms ķ̄imijterapijas uzsākšanas. Rīgas Stradiṇa universitātes 2018. gada zinātniskā konference, Rīga, Latvija, tēžu grāmata: 97 (Oral presentation).

3. Ceseiko, R., Eglitis, J., Srebnijs, A., Timofejevs, M., Purmalis, E., Vetra, A., Tomsone, S. Maximal strength training for breast cancer patients undergoing adjuvant treatment. Rīga Stradiņš University international conference "Knowledge For Use In Practice", 1.-3. aprīlis, 2019, Rīga, Latvija, tē̌̌u grāmata: 52 (Poster presentation). 


\section{References}

1. al-Majid, S. and McCarthy, D. O. (2001). Cancer-induced fatigue and skeletal muscle wasting: the role of exercise. Biol Res Nurs 2, 186-197.

2. Barrett-O'Keefe, Z., Helgerud, J., Wagner, P. D. and Richardson, R. S. (2012). Maximal strength training and increased work efficiency: contribution from the trained muscle bed. Journal of applied physiology (Bethesda, Md : 1985) 113, 18461851.

3. Battaglini, C., Bottaro, M., Dennehy, C., Rae, L., Shields, E., Kirk, D. and Hackney, A. C. (2007). The effects of an individualized exercise intervention on body composition in breast cancer patients undergoing treatment. Sao Paulo Med J 125, 22-28.

4. Battaglini, C. L., Hackney, A. C. and Goodwin, M. L. (2012). Cancer cachexia: muscle physiology and exercise training. Cancers (Basel) 4, 1247-1251.

5. Battaglini, C. L., Mills, R. C., Phillips, B. L., Lee, J. T., Story, C. E., Nascimento, M. G. and Hackney, A. C. (2014). Twenty-five years of research on the effects of exercise training in breast cancer survivors: A systematic review of the literature. World journal of clinical oncology 5, 177-190.

6. Behm, D .G. and Sale, D. G. (1993). Intended rather than actual movement velocity determines velocity-specific training response. Journal of applied physiology (Bethesda, Md : 1985) 74, 359-368.

7. Berg, H. E., Larsson, L. and Tesch, P. A. (1997). Lower limb skeletal muscle function after 6 wk of bed rest. J Appl Physiol (1985) 82, 182-188.

8. Berg, O. K., Nyberg, S. K., Windedal, T. M. and Wang, E. (2018). Maximal strength training-induced improvements in forearm work efficiency are associated with reduced blood flow. Am J Physiol Heart Circ Physiol 314, H853-h862.

9. Berger, A. M., Gerber, L. H. and Mayer, D. K. (2012). Cancer-related fatigue: implications for breast cancer survivors. Cancer 118, 2261-2269.

10. Bray, F., Ferlay, J., Soerjomataram, I., Siegel, R. L., Torre, L. A. and Jemal, A. (2018). Global cancer statistics 2018: GLOBOCAN estimates of incidence and mortality worldwide for 36 cancers in 185 countries. CA Cancer J Clin 68, 394-424.

11. Buffart, L. M., Sweegers, M. G., de Ruijter, C. J., Konings, I. R., Verheul, H. M., van Zweeden, A. A., Grootscholten, C., Chinapaw, M. J. and Altenburg, T. M. (2020). Muscle contractile properties of cancer patients receiving chemotherapy: Assessment of feasibility and exercise effects. Scandinavian Journal of Medicine \& Science in Sports 30, 1918-1929.

12. Burckart, K., Beca, S., Urban, R. J. and Sheffield-Moore, M. (2010). Pathogenesis of muscle wasting in cancer cachexia: targeted anabolic and anticatabolic therapies. Curr Opin Clin Nutr Metab Care 13, 410-416. 
13. Campbell, K. L., Neil, S. E. and Winters-Stone, K. M. (2012). Review of exercise studies in breast cancer survivors: attention to principles of exercise training. $\mathrm{Br} \mathrm{J}$ Sports Med 46, 909-916.

14. Cheema, B., Gaul, C. A., Lane, K. and Fiatarone Singh, M. A. (2008). Progressive resistance training in breast cancer: a systematic review of clinical trials. Breast cancer research and treatment 109, 9-26.

15. Christensen, J. F., Jones, L. W., Andersen, J. L., Daugaard, G., Rorth, M. and Hojman, P. (2014). Muscle dysfunction in cancer patients. Ann Oncol 25, 947-958.

16. Christensen, J. F., Simonsen, C. and Hojman, P. (2018). Exercise Training in Cancer Control and Treatment. Compr Physiol 9, 165-205.

17. Cornette, T., Vincent, F., Mandigout, S., Antonini, M.-T., Leobon, S., Labrunie, A., Venat, L., Lavau-Denes, S. and Tubiana-Mathieu, N. (2016). Effects of home-based exercise training on VO2 in breast cancer patients under adjuvant or neoadjuvant chemotherapy (SAPA): a randomized controlled trial. European journal of physical and rehabilitation medicine 52, 223-232.

18. Courneya, K. S., Segal, R. J., Mackey, J. R., Gelmon, K., Reid, R. D., Friedenreich, C. M., Ladha, A. B., Proulx, C., Vallance, J. K. and Lane, K. (2007a). Effects of aerobic and resistance exercise in breast cancer patients receiving adjuvant chemotherapy: a multicenter randomized controlled trial. Journal of clinical oncology 25, 4396-4404.

19. Courneya, K. S., Segal, R. J., Mackey, J. R., Gelmon, K., Reid, R. D., Friedenreich, C. M., Ladha, A. B., Proulx, C., Vallance, J. K., Lane, K., et al. (2007b). Effects of aerobic and resistance exercise in breast cancer patients receiving adjuvant chemotherapy: a multicenter randomized controlled trial. J Clin Oncol 25, 43964404 .

20. Courneya, K. S., Segal, R. J., McKenzie, D. C., Dong, H., Gelmon, K., Friedenreich, C. M., Yasui, Y., Reid, R. D., Crawford, J. J. and Mackey, J. R. (2014). Effects of exercise during adjuvant chemotherapy on breast cancer outcomes. Medicine and science in sports and exercise 46, 1744-1751.

21. De Backer, I. C., van Breda, E., Vreugdenhil, A., Nijziel, M. R., Kester, A. D. and Schep, G. (2007). High-intensity strength training improves quality of life in cancer survivors. Acta oncologica (Stockholm, Sweden) 46, 1143-1151.

22. Deschenes, M. R., Giles, J. A., McCoy, R. W., Volek, J. S., Gomez, A. L. and Kraemer, W. J. (2002). Neural factors account for strength decrements observed after short-term muscle unloading. Am J Physiol Regul Integr Comp Physiol 282, R578-583.

23. Egan, B. and Zierath, J. R. (2013). Exercise metabolism and the molecular regulation of skeletal muscle adaptation. Cell metabolism 17, 162-184.

24. Endo, Y., Nourmahnad, A. and Sinha, I. (2020). Optimizing Skeletal Muscle Anabolic Response to Resistance Training in Aging. Frontiers in Physiology 11. 
25. Fairman, C. M., Hyde, P. N. and Focht, B. C. (2017). Resistance training interventions across the cancer control continuum: a systematic review of the implementation of resistance training principles. Br J Sports Med 51, 677-685.

26. Fanzani, A., Conraads, V. M., Penna, F. and Martinet, W. (2012). Molecular and cellular mechanisms of skeletal muscle atrophy: an update. J Cachexia Sarcopenia Muscle 3, 163-179.

27. Folland, J. P. and Williams, A. G. (2007). The adaptations to strength training : morphological and neurological contributions to increased strength. Sports Med 37, 145-168.

28. Guigni, B. A., Callahan, D. M., Tourville, T. W., Miller, M. S., Fiske, B., Voigt, T., Korwin-Mihavics, B., Anathy, V., Dittus, K. and Toth, M. J. (2018). Skeletal muscle atrophy and dysfunction in breast cancer patients: role for chemotherapy-derived oxidant stress. Am J Physiol Cell Physiol 315, C744-c756.

29. Hagstrom, A. D., Shorter, K. A. and Marshall, P. W. M. (2019). Changes in Unilateral Upper Limb Muscular Strength and Electromyographic Activity After a 16-Week Strength Training Intervention in Survivors of Breast Cancer. J Strength Cond Res 33, 225-233.

30. Heggelund, J., Fimland, M. S., Helgerud, J. and Hoff, J. (2013). Maximal strength training improves work economy, rate of force development and maximal strength more than conventional strength training. Eur J Appl Physiol 113, 1565-1573.

31. Helgerud, J., Karlsen, T., Kim, W. Y., Høydal, K. L., Støylen, A., Pedersen, H., Brix, L., Ringgaard, S., Kværness, J. and Hoff, J. (2011). Interval and strength training in CAD patients. Int J Sports Med 32, 54-59.

32. Hoff, J., Gran, A. and Helgerud, J. (2002). Maximal strength training improves aerobic endurance performance. Scandinavian journal of medicine \& science in sports $12,288-295$.

33. Hoff, J., Tjønna, A. E., Steinshamn, S., Høydal, M., Richardson, R. S. and Helgerud, J. (2007). Maximal strength training of the legs in COPD: a therapy for mechanical inefficiency. Med Sci Sports Exerc 39, 220-226.

34. Irwin, M. L., Crumley, D., McTiernan, A., Bernstein, L., Baumgartner, R., Gilliland, F. D., Kriska, A. and Ballard-Barbash, R. (2003). Physical activity levels before and after a diagnosis of breast carcinoma: the Health, Eating, Activity and Lifestyle (HEAL) study. Cancer 97, 1746-1757.

35. Yakovenko, A., Cameron, M. and Trevino, J. G. (2018). Molecular therapeutic strategies targeting pancreatic cancer induced cachexia. World J Gastrointest Surg 10, 95-106.

36. Johns, N., Stephens, N. A. and Fearon, K. C. (2013). Muscle wasting in cancer. Int J Biochem Cell Biol 45, 2215-2229.

37. Karimi, M. and Brazier, J. (2016). Health, Health-Related Quality of Life and Quality of Life: What is the Difference? PharmacoEconomics 34, 645-649. 
38. Kim, H. K., Konishi, M., Takahashi, M., Tabata, H., Endo, N., Numao, S., Lee, S. K., Kim, Y. H., Suzuki, K. and Sakamoto, S. (2015). Effects of Acute Endurance Exercise Performed in the Morning and Evening on Inflammatory Cytokine and Metabolic Hormone Responses. PLoS One 10, e0137567.

39. Klassen, O., Schmidt, M. E., Ulrich, C. M., Schneeweiss, A., Potthoff, K., Steindorf, K. and Wiskemann, J. (2017). Muscle strength in breast cancer patients receiving different treatment regimes. J Cachexia Sarcopenia Muscle 8, 305-316.

40. Knaggs, J. D., Larkin, K. A. and Manini, T. M. (2011). Metabolic cost of daily activities and effect of mobility impairment in older adults. Journal of the American Geriatrics Society 59, 2118-2123.

41. L.R.V.K. (2018). Latvijas Republikas Valsts kontrole. Revīzijas ziņojums "Vai medicīniskā rehabilitācija tiek sniegta pacientiem, kam tā ir vajadz̄ìa, un pareizajā laikā?". Iegūts no: http://wwwlrvkgovlv/uploads/reviziju-zinojumi/2016/24144 2016/Revizijas\%20zinojums_Mediciniska\%20rehabilitacija_07122018pdf [sk. 24.02.2020].

42. Lindle, R. S., Metter, E. J., Lynch, N. A., Fleg, J. L., Fozard, J. L., Tobin, J., Roy, T. A. and Hurley, B. F. (1997). Age and gender comparisons of muscle strength in 654 women and men aged 20-93 yr. J Appl Physiol (1985) 83, 1581-1587.

43. Lira, F. S., Yamashita, A. S., Rosa, J. C., Tavares, F. L., Caperuto, E., Carnevali, L. C., Jr., Pimentel, G. D., Santos, R. V., Batista, M. L., Jr., Laviano, A., et al. (2011). Hypothalamic inflammation is reversed by endurance training in anorecticcachectic rats. Nutr Metab (Lond) 8, 60.

44. Mazzuca, F., Onesti, C. E., Roberto, M., Di Girolamo, M., Botticelli, A., Begini, P., Strigari, L., Marchetti, P. and Muscaritoli, M. (2018). Lean body mass wasting and toxicity in early breast cancer patients receiving anthracyclines. Oncotarget 9, 25714-25722.

45. McAuley, E., Blissmer, B., Katula, J., Duncan, T. E. and Mihalko, S. L. (2000). Physical activity, self-esteem and self-efficacy relationships in older adults: a randomized controlled trial. Annals of behavioral medicine: a publication of the Society of Behavioral Medicine 22, 131-139.

46. McTiernan, A., Friedenreich, C. M., Katzmarzyk, P. T., Powell, K. E., Macko, R., Buchner, D., Pescatello, L. S., Bloodgood, B., Tennant, B., Vaux-Bjerke, A., et al. (2019). Physical Activity in Cancer Prevention and Survival: A Systematic Review. Med Sci Sports Exerc 51, 1252-1261.

47. Mijwel, S., Backman, M., Bolam, K. A., Jervaeus, A., Sundberg, C .J., Margolin, S., Browall, M., Rundqvist, H. and Wengstrom, Y. (2018a). Adding high-intensity interval training to conventional training modalities: optimizing health-related outcomes during chemotherapy for breast cancer: the OptiTrain randomized controlled trial. Breast cancer research and treatment 168, 79-93.

48. Mijwel, S., Backman, M., Bolam, K. A., Olofsson, E., Norrbom, J., Bergh, J., Sundberg, C. J., Wengström, Y. and Rundqvist, H. (2018b). Highly favorable 
physiological responses to concurrent resistance and high-intensity interval training during chemotherapy: the OptiTrain breast cancer trial. Breast cancer research and treatment $169,93-103$.

49. Mijwel, S., Cardinale, D. A., Norrbom, J., Chapman, M., Ivarsson, N., Wengström, Y., Sundberg, C. J. and Rundqvist, H. (2018c). Exercise training during chemotherapy preserves skeletal muscle fiber area, capillarization and mitochondrial content in patients with breast cancer. Faseb j 32, 5495-5505.

50. Møller, T., Andersen, C., Lillelund, C., Bloomquist, K., Christensen, K .B., Ejlertsen, B., Tuxen, M., Oturai, P., Breitenstein, U., Kolind, C., et al. (2020). Physical deterioration and adaptive recovery in physically inactive breast cancer patients during adjuvant chemotherapy: a randomised controlled trial. Scientific Reports 10,9710.

51. Montalvo, R. N., Hardee, J. P., VanderVeen, B. N. and Carson, J. A. (2018). Resistance Exercise's Ability to Reverse Cancer-Induced Anabolic Resistance. Exerc Sport Sci Rev 46, 247-253.

52. Moreland, J. D., Richardson, J. A., Goldsmith, C. H. and Clase, C. M. (2004). Muscle weakness and falls in older adults: a systematic review and meta-analysis. J Am Geriatr Soc 52, 1121-1129.

53. Mutrie, N., Campbell, A. M., Whyte, F., McConnachie, A., Emslie, C., Lee, L., Kearney, N., Walker, A. and Ritchie, D. (2007). Benefits of supervised group exercise programme for women being treated for early stage breast cancer: pragmatic randomised controlled trial. BMJ 334, 517-517.

54. Nygard, M., Mosti, M. P., Brose, L., Flemmen, G., Stunes, A. K., Sorskar-Venaes, A., Heggelund, J. and Wang, E. (2018). Maximal strength training improves musculoskeletal health in amphetamine users in clinical treatment. Osteoporosis international : a journal established as result of cooperation between the European Foundation for Osteoporosis and the National Osteoporosis Foundation of the USA 29, 2289-2298.

55. Prado, C. M., Antoun, S., Sawyer, M. B. and Baracos, V. E. (2011). Two faces of drug therapy in cancer: drug-related lean tissue loss and its adverse consequences to survival and toxicity. Current Opinion in Clinical Nutrition \& Metabolic Care 14, 250-254.

56. Rejeski, W. J., Miller, M. E., King, A. C., Studenski, S. A., Katula, J. A., Fielding, R. A., Glynn, N. W., Walkup, M. P., Ashmore, J. A. and Investigators, L. (2007). Predictors of adherence to physical activity in the Lifestyle Interventions and Independence for Elders pilot study (LIFE-P). Clin Interv Aging 2, 485-494.

57. Schmidt, T., Weisser, B., Duerkop, J., Jonat, W., van Mackelenbergh, M., Roecken, C. and Mundhenke, C. (2015). Comparing endurance and resistance training with standard care during chemotherapy for patients with primary breast cancer. Anticancer research 35, 5623-5629. 
58. Schmitz, K. H., Courneya, K. S., Matthews, C., Demark-Wahnefried, W., Galvao, D. A., Pinto, B. M., Irwin, M. L., Wolin, K. Y., Segal, R. J., Lucia, A., et al. (2010). American College of Sports Medicine roundtable on exercise guidelines for cancer survivors. Medicine and science in sports and exercise 42, 1409-1426.

59. Schwartz, A. L. and Winters-Stone, K. (2009). Effects of a 12-month randomized controlled trial of aerobic or resistance exercise during and following cancer treatment in women. The Physician and Sportsmedicine 37, 62-67.

60. Segal, R. J., Reid, R. D., Courneya, K. S., Malone, S. C., Parliament, M. B., Scott, C. G., Venner, P. M., Quinney, H. A., Jones, L. W., D'Angelo, M. E., et al. (2003). Resistance exercise in men receiving androgen deprivation therapy for prostate cancer. Journal of clinical oncology : official journal of the American Society of Clinical Oncology 21, 1653-1659.

61. Støren, O., Helgerud, J., Støa, E. M. and Hoff, J. (2008). Maximal strength training improves running economy in distance runners. Med Sci Sports Exerc 40, 1087- 1092.

62. Suetta, C., Magnusson, S. P., Rosted, A., Aagaard, P., Jakobsen, A. K., Larsen, L. H., Duus, B. and Kjaer, M. (2004). Resistance training in the early postoperative phase reduces hospitalization and leads to muscle hypertrophy in elderly hip surgery patients--a controlled, randomized study. Journal of the American Geriatrics Society 52, 2016-2022.

63. Suzuki, K. (2018). Cytokine Response to Exercise and Its Modulation. Antioxidants (Basel) 7, 17.

64. Thompson, L. V. (2002). Skeletal muscle adaptations with age, inactivity and therapeutic exercise. J Orthop Sports Phys Ther 32, 44-57.

65. Toien, T., Pedersen Haglo, H., Unhjem, R., Hoff, J. and Wang, E. (2018). Maximal strength training: the impact of eccentric overload. Journal of neurophysiology 120 , 2868-2876.

66. Travier, N., Velthuis, M. J., Bisschop, C. N. S., van den Buijs, B., Monninkhof, E. M., Backx, F., Los, M., Erdkamp, F., Bloemendal, H. J. and Rodenhuis, C. (2015). Effects of an 18-week exercise programme started early during breast cancer treatment: a randomised controlled trial. BMC medicine 13, 121.

67. Unhjem, R., Flemmen, G., Hoff, J. and Wang, E. (2016). Maximal strength training as physical rehabilitation for patients with substance use disorder; a randomized controlled trial. BMC Sports Sci Med Rehabil 8, 7-7.

68. Unhjem, R., Nygård, M., Hoff, J. and Wang, E.J.J.o.g.p.t. (2017). Functional Performance With Age: The Role of Long-Term Strength Training.

69. Van Waart, H., Stuiver, M. M., van Harten, W. H., Geleijn, E., Kieffer, J. M., Buffart, L. M., de Maaker-Berkhof, M., Boven, E., Schrama, J. and Geenen, M. M. (2015a). Effect of low-intensity physical activity and moderate-to high-intensity physical exercise during adjuvant chemotherapy on physical fitness, fatigue and 
chemotherapy completion rates: results of the PACES randomized clinical trial. J Clin Oncol 33, 1918-1927.

70. Van Waart, H., Stuiver, M. M., van Harten, W. H., Geleijn, E., Kieffer, J. M., Buffart, L. M., de Maaker-Berkhof, M., Boven, E., Schrama, J., Geenen, M. M., et al. (2015b). Effect of Low-Intensity Physical Activity and Moderate- to HighIntensity Physical Exercise During Adjuvant Chemotherapy on Physical Fitness, Fatigue and Chemotherapy Completion Rates: Results of the PACES Randomized Clinical Trial. J Clin Oncol 33, 1918-1927.

71. Wang, E., Helgerud, J., Loe, H., Indseth, K., Kaehler, N. and Hoff, J. (2010). Maximal strength training improves walking performance in peripheral arterial disease patients. Scand J Med Sci Sports 20, 764-770.

72. Wang, E., Nyberg, S. K., Hoff, J., Zhao, J., Leivseth, G., Tørhaug, T., Husby, O. S., Helgerud, J. and Richardson, R. S. (2017). Impact of maximal strength training on work efficiency and muscle fiber type in the elderly: Implications for physical function and fall prevention. Exp Gerontol 91, 64-71.

73. Wernbom, M., Augustsson, J. and Thomeé, R. (2007). The influence of frequency, intensity, volume and mode of strength training on whole muscle cross-sectional area in humans. Sports Med 37, 225-264.

74. Winters-Stone, K. M., Dobek, J., Nail, L. M., Bennett, J. A., Leo, M. C., Torgrimson-Ojerio, B., Luoh, S. W. and Schwartz, A. (2013). Impact + resistance training improves bone health and body composition in prematurely menopausal breast cancer survivors: a randomized controlled trial. Osteoporos Int 24, 1637- 1646 . 


\section{Acknowledgments}

I would like to express my deepest gratitude to all patients that participated in the study, your commitment and trust were much respected.

To my supervisor, Professor Eivind Wang, thank you for your support and trust through these years. Your work ethic and passion allowed me to gradually become better a young researcher. I appreciate your commitment to me and your positive decision to be my supervisor.

To Associate Professor Signe Tomsone, thank you for your open heart and warm support, not only during Doctoral studies but also previously when leading the occupational therapy field at university. Thank you for accepting me as your Doctoral student and being open to such a new research field. I am also happy and thankful for giving me the opportunities and support to become a member of the Rehabilitation faculty.

To Professor Jānis Eglītis, thank you for being open and without a doubt letting me in your Breast Surgery Department with training equipment. I am very happy that we had a chance to visit and share our results with the Worldwide oncology community. Additionally, I appreciate all the fantastic doctors and staff of your department that accepted me and contributed to my study progress.

Professor Aivars Vètra, thank you for giving me many opportunities to get involved in different fields of rehabilitation, I appreciate your trust in me and mutual respect.

To MD. Marija Petroviča, thank you for your support, time and valuable advice.

Deepest gratitude to my family, for being present in this journey.

Last but not least, I am very thankful to Rīga Stradiņš University for the support and environment to manage this study and to grow as a new researcher. 